\title{
The Science and Practice of Bone Health in Oncology: Managing Bone Loss and Metastasis in Patients With Solid Tumors
}

\author{
Allan Lipton, MD; Robert Uzzo, MD, FACS; Robert J. Amato, MD; Georgiana K. Ellis, MD; \\ Behrooz Hakimian, MD; G. David Roodman, MD, PhD; and Matthew R. Smith, MD, PhD; \\ Hershey, Pennsylvania; Philadelphia, Pennsylvania; Houston, Texas; Seattle, Washington; Los Angeles, California; \\ Pittsburgh, Pennsylvania; and Boston, Massachusetts
}

\section{Key Words}

Biochemical markers, bisphosphonates, bone health, bone metabolism, bone metastasis, bone pain, breast cancer, chemotherapy-induced bone loss, denosumab, metastatic cancer, multiple myeloma, osteoporosis, prostate cancer, RANKL

\begin{abstract}
Cancer and its treatment can compromise bone health, leading to fracture, pain, loss of mobility, and hypercalcemia of malignancy. Bone metastasis occurs frequently in advanced prostate and breast cancers, and bony manifestations are commonplace in multiple myeloma. Osteoporosis and osteopenia may be consequences of androgen-deprivation therapy for prostate cancer, aromatase inhibition for breast cancer, or chemotherapy-induced ovarian failure. Osteoporotic bone loss and bone metastasis ultimately share a pathophysiologic pathway that stimulates bone resorption by increasing the formation and activity of osteoclasts. Important mediators of pathologic bone metabolism include substances produced by osteoblasts, such as RANKL, the receptor activator of nuclear factor kappa B ligand, which spurs osteoclast differentiation from myeloid cells. Available therapies are targeted to various steps in cascade of bone metastasis. (JNCCN 2009;7[Suppl 7]:S1-S29)
\end{abstract}

\section{Bone Disease: A Growing Problem}

Osteoporosis and osteopenia are common clinical problems associated with aging. ${ }^{1}$ Concurrent with these risks is malignant bony metastases. The skeleton is a frequent target of metastatic disease. It can be the first and sometimes the only site of advanced disease, contributing greatly to the burden of care in cancer patients. ${ }^{2,3}$ Bone metastases may complicate a wide range of malignancies, causing considerable morbidity and costly demands on health care resources. That certain tumors have a more predictable pattern of spread is well recognized. ${ }^{4}$ Prostate cancer, breast cancer, and multiple myeloma have a particularly strong association with skeletal metastases and related bone loss, resulting in fracture, hypercalcemia, pain, and declines in mobility and performance status. ${ }^{5-7}$ Attention to bone health has emerged as an important and under-recognized component of comprehensive cancer care.

Bone metastases most commonly affect the axial skeleton. Hematogenous spread is the most likely route, caused by venous drainage from visceral organs directly into the axial bones. Early postmortem studies of animals and humans by Batson ${ }^{8}$ showed that venous blood from the breasts and pelvic organs, like the prostate, flowed not only into the vena cava, but also into a vertebral-venous (Batson's) plexus of vessels extending from the pelvis throughout the epidural and perivertebral veins. These direct hematogenous routes may explain in part the high proclivity of breast and prostate cancers to involve the axial skeleton. However, in the bone, it is the interaction between the molecular and cellular characteristics of the tumor cells and the bony microenvironment that ultimately influence metastatic skeletal growth. ${ }^{9,10}$

Morbidity associated with metastatic bony lesions can be extensive, regardless of the primary tumor origin..$^{2,3}$ Osteolytic lesions, the type most commonly seen in breast cancer, can cause severe pain, pathologic fracture, and compression syndromes of the nerve root or spinal cord, as well as metabolic disturbances, such as hypercalcemia, phosphate imbalances, disruptions in 
Lipton et al.

acid/base and neurological homeostasis, and nephrolithiasis. ${ }^{211,12}$ Osteoblastic lesions such as those seen in prostate cancer have also been associated with similar problematic clinical events. ${ }^{2,12}$ Patients can exhibit a combination of osteolytic and osteoblastic lesions. Mixed lesions cause increased bone resorption (via osteoclasts) within osteoblastic lesions and compensatory, secondary bone formation (via osteoblasts) within osteolytic lesions. ${ }^{2,3}$

Bone metastases are particularly prevalent in breast and prostate cancers and an important cause of morbidity (Table 1). ${ }^{3,13}$ Skeletal metastases affect $65 \%$ to $75 \%$ of men with advanced disease, and postmortem studies show that this number may be even higher in those who die of the disease. . $^{3,13,14}$ This problem is compounded by the fact that the most common treatments for advanced prostate cancer further predispose patients to bone loss and skeletalrelated events (SREs). ${ }^{15}$

The most commonly used therapeutic strategy for men with advanced prostate cancer, androgen deprivation therapy (ADT), increases bone turnover and decreases bone mineral density (BMD), leading to a $20 \%$ to $45 \%$ increase in relative fracture risk. ${ }^{5,16,17}$ Among 1139 men aged 70 years or older receiving ADT for prostate cancer (mean treatment duration, 39 months), 55\% had osteopenia and 18\% had osteoporosis. ${ }^{18}$ In addition, the older age of this patient population and the propensity of these men to develop cardiovascular disease further compound the vulnerability of their bones in the context of metastases. When taken together, these factors increase the risk of bone complications, independent of the treatment patients receive. ${ }^{15}$

\begin{tabular}{|l|l|}
$\begin{array}{l}\text { Table } 1 \\
\text { Incidence of Bone Metastasis in } \\
\text { Advanced Cancer, by Cancer Type }\end{array}$ \\
$\begin{array}{l}\text { Incidence of Bone } \\
\text { Metastasis Among Patients } \\
\text { with Metastatic Disease }\end{array}$ \\
\hline Cancer Type & $90 \%-100 \%$ \\
Bultiple myeloma & $65 \%-75 \%$ \\
Prostate cancer & $65 \%-75 \%$ \\
Lung cancer & $30 \%-40 \%$ \\
Bladder cancer & $40 \%$ \\
Kidney cancer & $20 \%-25 \%$ \\
Thyroid cancer & $60 \%$ \\
Melanoma & $14 \%-45 \%$ \\
\hline
\end{tabular}

Bone metastases are also extremely common in women with breast cancer, developing in $65 \%$ to $75 \%$ of those with advanced disease (Table 1).,13 As with prostate cancer, bone loss in breast cancer patients is the result of both the disease and its therapeutic interventions. For example, aromatase inhibitors (AIs), widely used for estrogen receptor (ER)-positive breast cancer, increase the risk for osteoporosis. ${ }^{6}$ Because breast cancer is most likely to affect postmenopausal women, this population also carries a high age- and gender-based risk for bone loss and osteoporotic fracture associated with estrogen decline. ${ }^{19}$ Moreover, women with chemotherapy-induced ovarian failure are at further risk for osteoporosis. ${ }^{1}$

Unlike prostate or breast cancers, multiple myeloma originates within the bone marrow. By the time patients present with active (symptomatic) disease, $80 \%$ have associated bony destruction. ${ }^{7}$ Skeletal manifestations of multiple myeloma-osteopenia and osteolytic lesions-eventually develop in most patients, compromising both performance status and quality of life. ${ }^{3,7,13}$

Bone loss in cancer patients is multifactorial, resulting from the disease and its treatments in the context of age-related bone alterations. However, ultimately, common pathways of pathological bone metabolism characterize both bone loss and metastases. Understanding these pathophysiologic mechanisms has resulted directly in current and emerging therapies that support bone health across the spectrum of cancer. As the pathways of bony metabolism and resorption are elucidated, several strategies to intervene for therapeutic benefit have emerged. Notable emerging therapies include mechanisms that bind to the receptor activator of nuclear factor kappa B ligand (RANKL) to suppress osteoclastogenesis and thereby inhibit bone resorption and mechanisms that stimulate osteoblastic bone formation while inhibiting osteoblastic resorption. More therapies are in development.

\section{Bone Metabolism in Cancer}

\section{Normal and Pathologic Bone Metabolism}

In the healthy adult skeleton, bone maintenance is a coordinated, dynamic balance between bone resorption and bone formation. Formation involves osteoblasts, differentiated cells of mesenchymal origin that produce the calcified bony matrix, and osteocalcin. 
Osteoblasts secrete a host of regulatory factors integral to bone metabolism, which include macrophage colony-stimulating factor (M-CSF) and RANKL. In turn, the growth and differentiation of osteoblasts is enhanced by various factors, including platelet-derived growth factor, fibroblast growth factor (FGF), and transforming growth factor- $\beta$ (TGF- $\beta$ ). An osteoblast precursor generates alkaline phosphatase, which is a serum marker elevated in patients with bone metastases and fracture. ${ }^{2}$

The resorption of old bone is as important to skeletal homeostasis as the formation of new bone. Resorption involves the osteoclasts, large cells originating in the bone marrow. The osteoclast has a characteristic ruffled border that optimizes contact and adherence to the bony matrix. These cells resorb bone by secreting enzymes that break down the organic portions of the matrix (i.e., collagen) and by increasing local acidity, which dissolves the bone minerals. ${ }^{2}$

The process of osteoclast formation and activation requires a complex cascade of growth and necrosis factors, as well as paracrine and endocrine hormonal activity (Figure 1). Important mediators include RANKL and colony stimulating factors (such as M-CSF), TGF- $\beta$, interleukins, and prostaglandins, all of which are secreted by osteoblasts. Two of the most important factors, RANKL and MCSF, are also secreted by stromal cells that neighbor osteoclast precursors in bone marrow. ${ }^{2}$

RANKL is a member of the family of tumor necrosis factors (TNFs). The expression of RANKL on stromal cells and osteoblasts is regulated by osteotropic substances, including parathyroid hormone; 1,25-dihydroxyvitamin $\mathrm{D}_{3}$; and prostaglandins. RANKL binds to its receptor (RANK) on osteoclast precursors, inducing the differentiation of osteoclasts from myeloid cells through signaling by way of nuclear factor kappa B and Jun N-terminal kinase pathways. ${ }^{2}$

Binding of RANKL to RANK is endogenously inhibited by osteoprotegerin, another TNF expressed by the osteoblast, which is present in bone marrow. Osteoprotegerin acts as a decoy receptor. Thus, the ratio of RANKL to osteoprotegerin regulates osteoclast formation, and the higher the ratio, the more osteoclasts form (Figure 2). ${ }^{2} \mathrm{M}$-CSF acts by binding to associated receptors (c-Fms). ${ }^{20}$ Receptor activation and signaling by M-CSF triggers proliferation of osteoclast precursors in the bone marrow. M-CSF also mediates differentiation of these precursors into osteoclasts..$^{20,21}$

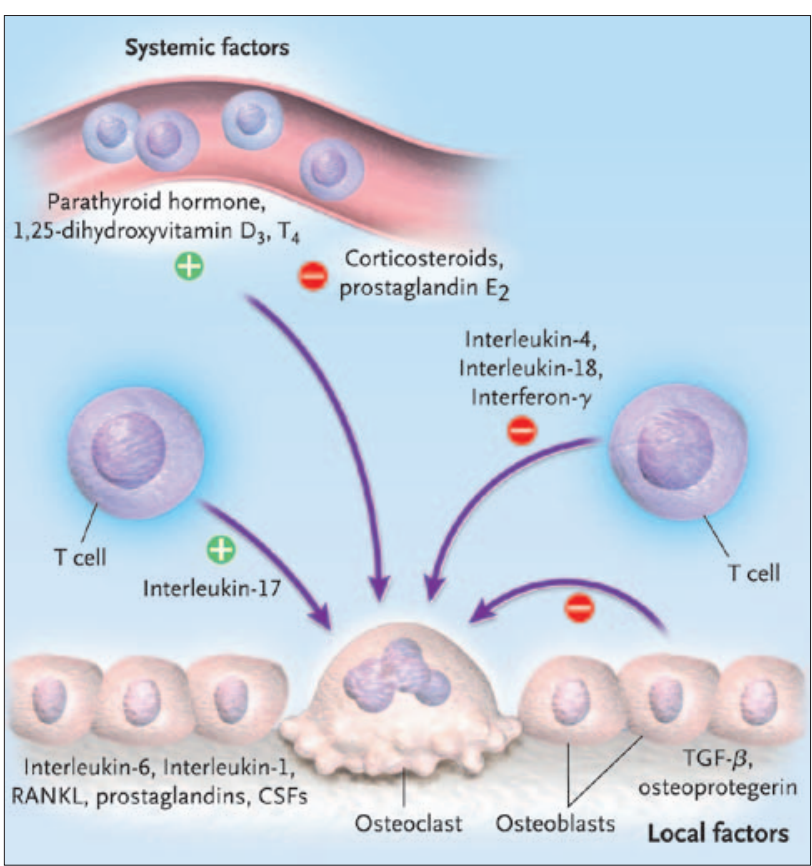

Figure 1 Bone resorption: the osteoclast.

Abbreviations: CSF, colony-stimulating factor; RANKL, receptor activator of nuclear factor kappa B ligand; TGF- $\beta$, transforming growth factor $\beta$.

Reproduced with permission from Roodman GD. Mechanisms of bone metastasis. N Engl J Med 2004;350:1655-1664.

In patients with cancer, these normal mechanisms of bone metabolism can be significantly disrupted by metastases or treatments. Ultimately, both events alter bone homeostasis, particularly osteoclastic bone resorption.

\section{Bone Metastasis}

Four types of cells are involved in establishing bone metastases: cancer cells, osteoblasts, osteoclasts, and mineralized bone matrix, a major source of immobilized growth factors. A hallmark of all metastatic bone lesions is the increase in bone resorption by osteoclasts, mimicking similar mechanisms involved in osteoporosis. ${ }^{3}$

Malignant bone lesions are classified by their radiographic appearance as osteolytic (bony destruction), osteoblastic (a buildup of new, weaker bone), or mixed. ${ }^{1,3}$ Morbidity is similar across subtypes, and all possess an osteoclastic lineage. ${ }^{1,3,12}$ Tumor cells produce substances that can directly stimulate osteoclasts, such as interleukin-8 or TNFs, leading to increased bone resorption and osteolytic lesions. ${ }^{1}$ Metastasis changes the skeletal microenvironment, because tumor cells express factors that act on os- 


\section{Lipton et al.}

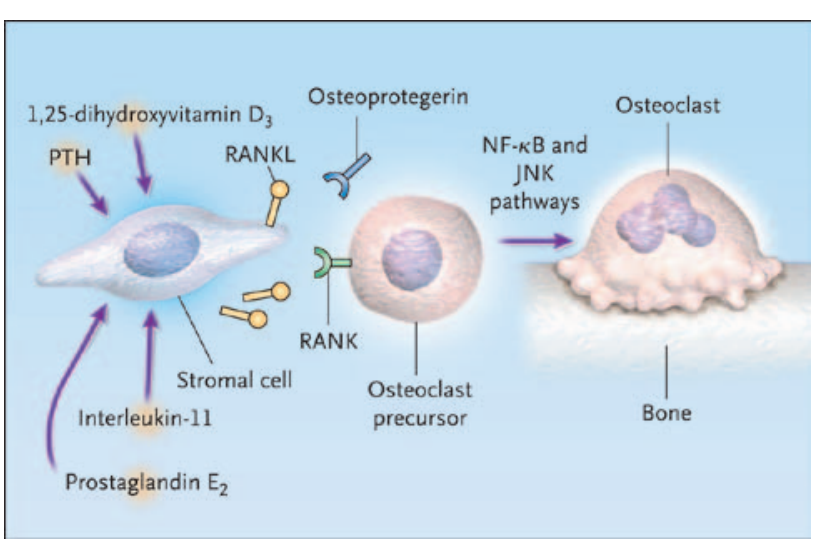

Figure 2 RANKL in osteoclast formation.

Abbreviations: JNK, Jun N-terminal kinase; NF-kB, nuclear factor kappa B; PTH, parathyroid hormone; RANK, receptor activator of nuclear factor kappa B; RANKL, receptor activator of nuclear factor kappa B ligand.

Reproduced with permission from Roodman GD. Mechanisms of bone metastasis. N Engl J Med 2004;350:1655-1664.

teoblasts to increase production of RANKL and decrease production of osteoprotegerin, thereby increasing the RANKL to osteoprotegerin ratio to accelerate osteoclast formation and bone resorption. ${ }^{1,12}$ As osteoclasts resorb bone, TGF- $\beta$ dissociates from the bony matrix to drive the genesis of osteoblasts and their production of RANKL, which stimulates even more osteoclastic bone resorption. Finally, migrating tumor cells may have a direct effect on osteoblasts, leading to the over-formation of new bone characteristic of osteoblastic lesions. ${ }^{2}$

The mechanisms of bone metastasis in prostate and breast cancers have been studied intensively. ${ }^{2,12}$ Bone metastasis in breast cancer is characterized by osteolytic bone lesions. ${ }^{11,12}$ These lesions are indicative of marked osteoclast activity. The aggressive resorption of bone by osteoclasts in breast cancer leads to a feedback loop in which degradation products of bone stimulate both bone loss and growth of metastatic cells. ${ }^{12}$ For example, when osteoclasts resorb bone, release of TGF- $\beta$ not only promotes RANKL production and further osteoclast activity but also stimulates angiogenesis and other parts of the metastatic cascade. ${ }^{1}$ Other substances released by the dissolution of bone, such as insulin-like growth factor 1 , bone morphogenetic protein, and interleukin-11, are also part of the osteolysis-metastasis feedback loop. ${ }^{12}$

In contrast, prostate cancer often leads to excessive bone production and osteoblastic lesions; this phenomenon may be caused by the stimulation of osteoblasts by Wnt protein-bone morphogenetic protein signaling pathways. ${ }^{12,22}$ In addition, substances like endothelin-1, TGF- $\beta$, and fibroblast growth factor (FGF), which are synthesized by prostate cancer cells, may also influence bone morphology by promoting osteoblastogenesis. ${ }^{1,2,12}$ These processes lead not only to the formation of new bone but also to the release RANKL and other mediators of osteoclastic bone resorption. One especially interesting observation is that nuclear factor kappa B (the "NK" of RANK), when localized in the nucleus of the prostate cancer cell, predicts poorer outcomes, including a higher risk for progression to bone. ${ }^{23,24}$ In men with non-androgendependent prostate cancer and bone metastases, alkaline phosphatase correlates with urinary cross-linked $\mathrm{N}$-telopeptide of type I collagen (NTx), a marker of osteoclast activity. In general, higher levels of alkaline phosphatase reflect the burden of disease in the bone and thereby may predict shorter survival times. ${ }^{25}$

\section{Treatment-Related Bone Loss}

Declines in estrogen levels increase the ratio of RANKL to osteoprotegerin, which promotes osteoclastogenesis. ${ }^{26}$ Accelerating bone resorption and bone loss then leads to osteopenia and osteoporosis. This process occurs naturally in women as they make the transition to menopause, but also results from treatment with estrogen-depleting therapies for breast cancer, such as AIs. ${ }^{27}$ Ovarian failure after chemotherapy also depletes estrogen, promoting bone loss in a similar fashion.

In prostate cancer, therapeutic androgen deprivation leads to increased osteoclastic bone resorption and a progressive decrease in BMD. One proposed mechanism is that androgen deficiency promotes osteoclast formation. Androgens have been shown to inhibit both RANKL and M-CSF, which regulate osteoclast differentiation from precursors. Greater generation of osteoclasts induced by lower levels of androgen may lead to more bone resorption and loss. Androgens may also regulate genes involved in the activity of osteoblasts, influencing the counter-regulatory mechanism of the growth of the bony matrix. ${ }^{28}$

The relationship between androgen deprivation and bone loss is clinically relevant and often under-recognized in men with prostate cancer. A 2009 study found that total body BMD was inversely associated with the incidence of prostate cancer among men enrolled in a trial evaluating osteoporotic fracture risk. ${ }^{29}$ In this study, prostate cancer 
risk decreased with significantly increased BMD $(P$ $=.007)$. The trend derived predominantly from the population with high-grade prostate cancer; a strong inverse association was noted between total BMD and high-grade disease, but no associations were observed with low-grade disease. These results suggest a pathophysiologic link between prostate cancer and bone metabolism, which may be androgen-mediated.

Other possible factors to consider are poor vitamin D status and chronic inflammatory responses, which may be relatively common in patients with prostate cancer and bone demineralization. These results are a reminder that men with prostate cancer are predisposed to a loss in bone density that can be exacerbated by therapeutic androgen depletion. ${ }^{29}$

\section{Detection of and Monitoring for Bone Metastases}

Symptoms of bone metastasis can be the first indication of cancer, and the nature of bone metastases can help diagnose the primary tumor. Patients with a known primary tumor, particularly those mentioned in Table 1, should be monitored for bone metastases. ${ }^{2,13}$

\section{Presentation of Bone Metastases}

The first symptom of skeletal metastasis is typically bone pain. It can be intermittent at first, but gradually worsens and becomes constant. Bone pain is often worse at night, leading to sleep disturbance and fatigue. This type of pain must be differentiated from arthritis, fibromyalgia, and other conditions characterized by extensive pain. ${ }^{13}$

Severe back pain is another common presentation of bone metastasis, because the spine is frequently the first skeletal metastatic site. Spinal cord compression caused by the tumor pressing on the spinal cord can damage nerves if left untreated and should be addressed immediately. This could result in numbness, weakness, and difficulty urinating. ${ }^{13}$ Sudden, severe pain may indicate a fracture. In patients with metastases to the bone, fracture can be caused by a minor injury or fall, or even everyday activities, because of the weakness of the bone at metastatic sites. These fractures must be differentiated from vertebral fractures caused by osteoporosis. The ribs and long bones of the arms and legs are other common sites of fracture related to bone metastasis. ${ }^{13}$

Bone metastases can also present as hypercalcemia, because the cancer breaks down the bone, re- leasing calcium into the bloodstream. Symptoms of hypercalcemia include constipation, nausea, loss of appetite, and extreme thirst. Although it can be easily treated, hypercalcemia can rapidly lead to coma if left untreated. ${ }^{13}$

\section{Detecting Bone Metastases}

Diagnostic Imaging: There is currently no consensus on how to best identify suspected metastatic lesions in the skeleton. Traditionally, radiography and radionuclide bone scan (skeletal scintigraphy) were the most common and least expensive options. Although both are still useful in some circumstances, PET, CT, and MRI scans are becoming more popular as they come more available (Figure 3). ${ }^{30,31}$

Bone metastases are composed of osteolytic, osteoblastic, or mixed lesions. On radiographs, osteolytic lesions appear as dark spots and osteoblastic lesions appear whiter. However, at least $50 \%$ of the bone in a lesion must be compromised before it appears on radiography. Radiography can also be used to identify fractures in patients with sudden, severe bone pain. ${ }^{30,31}$

Injected technetium diphosphonate bone scans have historically been the standard for identifying bone metastases, which are indicated by dense gray to black "hot spots" on the scan. ${ }^{30,31}$ However, these hot spots can also be caused by prior trauma, infection, or degenerative joint disease, such as arthritis, so more-specific imaging techniques have become popular in recent years.

Studies have shown that the accuracy of bone scan reading can be improved with the use of a computer-assisted diagnosis system. ${ }^{32}$ Bone scans show metastatic sites much earlier than radiographs and can be used to track treatment progress; however, they may not show lesions that are purely osteolytic. Bone scans can also be used to corroborate or clarify suspected lesions found using other imaging modalities.

PET scans have greater sensitivity and specificity than bone scans and can identify smaller cancer cell deposits than other imaging techniques. PET has been shown to improve localization of metastatic lesions identified on bone scans, and to identify additional lesions. ${ }^{33}$ Because it is also used for staging some primary cancers, PET has replaced bone scans in many practices. ${ }^{30,31}$ In prostate cancer, however, studies show inconsistent results for 2-Deoxy-2-[18F] fluoro-D-glucose (FDG)-PET, despite its effectiveness in other tumor types. ${ }^{34,35}$ 
Lipton et al.

\begin{tabular}{|l|c|l|l|l|l|l|}
\hline & $\begin{array}{l}\text { Cortical } \\
\text { Bone }\end{array}$ & $\begin{array}{l}\text { Trabecular } \\
\text { Bone }\end{array}$ & $\begin{array}{l}\text { Bone } \\
\text { Marrow }\end{array}$ & Tumors & $\begin{array}{l}\text { Bone } \\
\text { Metabolism }\end{array}$ & $\begin{array}{l}\text { Tumor } \\
\text { Glucose } \\
\text { Metabolism }\end{array}$ \\
\hline X-ray & $\mathrm{X}$ & $\mathrm{X}$ & & & & \\
\hline CT & $\mathrm{X}$ & $\mathrm{X}$ & $\mathrm{X}$ & $\mathrm{X}$ & & \\
\hline MRI & & & $\mathrm{X}$ & $\mathrm{X}$ & & \\
\hline Bone scan & & & & & $\mathrm{X}$ & \\
\hline SPECT & & & & & $\mathrm{X}$ & \\
\hline PET & & \multicolumn{7}{|c|}{ Tumor Appearance } & $\mathrm{X}$ \\
\hline
\end{tabular}

Figure 3 Imaging modalities used to detect bone metastases.

Abbreviation: SPECT, single-photon emission CT.

Adapted from Hamaoka T, Madewell JE, Podoloff DA, et al. Bone imaging in metastatic breast cancer. J Clin Oncol 2004;22:2942-2953.

Unlike bone scans, CT scans will show osteolytic-only lesions. CT can be used in patients who cannot tolerate MRI and are also used for guided needle biopsy in the rare cases in which biopsy of the suspected metastatic lesion is necessary. ${ }^{30,31}$

Combining PET and CT scans can improve the sensitivity and specificity of each technique alone. A recent study showed PET-CT to be highly sensitive and specific in high-risk prostate cancer patients-better than PET alone or planar and single-photon emission computed tomography bone scintigraphy. ${ }^{36}$ PET-CT is useful in staging metastatic and recurrent disease, particularly lytic lesions in breast cancer; assessing early response to treatment; and clarifying indeterminate results of other imaging modalities. ${ }^{37,38} \mathrm{~A}$ recent study by Beheshti et al. ${ }^{39}$ showed promising results using $18 \mathrm{~F}$ fluorocholine (fluoromethyl-dimethyl-2-hydroxyethylammonium [FCH])-PET-CT for the early detection of bone metastases in prostate cancer patients.

MRI has become the standard test for detecting complications of spinal metastasis (e.g., spinal cord compression) and it also particularly useful for confirming suspected metastatic lesions at the shoulder, hips, and pelvis. ${ }^{31}$ In recent studies, MRI was better than bone scan for detecting metastatic lesions in a variety of primary cancers. ${ }^{40-43}$ At least one study also found MRI to be better for detecting bone metastases than PET-CT. ${ }^{44}$ However, the relative accuracy of MRI must be balanced against its high cost compared with traditional bone scans.

Biochemical Markers of Bone Turnover: Although no consensus has been reached on the usefulness of bone turnover markers for diagnosing bone metastases, high calcium and alkaline phosphatase levels on routine blood tests show an increase in bone turnover that could be related to skeletal metastatic lesions.

Other markers of bone turnover have been tested for diagnostic efficacy, including serum type I procollagen C-propeptide, tartrate-resistant acid phosphatase (TRAP), C-terminal telopeptide of type I collagen ( $\beta$-CTx), and urine NTx. The latter 2 tests have shown the most promise, but no standards have been established for using biochemical markers to diagnose bone metastases. ${ }^{2}$

Biopsy: In the most difficult cases, a biopsy may be required to diagnose skeletal metastasis, but this is rarely necessary. Needle biopsy is possible only if bone is weakened or the cancer has spread to the soft tissue around the bone. Surgical or incisional biopsy is rarely used. ${ }^{31}$

\section{Monitoring Patients Diagnosed With Primary Tumors}

The skeleton is the most common metastatic site in many cancers. Patients with cancer, especially breast or prostate cancers, should be carefully monitored for signs of metastasis to bone. Because some therapies can cause bone loss, prior treatment should also be considered when evaluating SREs in cancer patients. For example, radiologists need to know if a patient with breast cancer has taken bisphosphonates or received prior radiotherapy, because bisphosphonate use can affect the type of metastatic lesions a patient is likely to develop, and radiologic treatment can cause rib fractures that could be mistaken for distant recurrence. ${ }^{31,45}$ 
As cancer treatment and survival rates improve, bone metastases likely will be seen more frequently and accompanying more primary tumor types. Better diagnostic and treatment protocols for bone metastasis are beginning to be developed. For example, recently updated guidelines for lung cancer recommend that patients with resectable tumors be screened for bone metastases at initial diagnosis and staging, preferably using whole-body PET scan if available. ${ }^{46}$

Predicting Risk for Metastasis to Bone: Determining prognosis and stratifying patients by risk of progression are important for personalizing treatment and follow-up strategies. Patients in whom the bones are the only metastatic site may have better survival rates than those whose cancer spreads to soft tissues. In a study of 367 patients with bone metastases from breast cancer, those who later developed extraosseous disease had a median survival of 1.6 years, compared with 2.1 years for those with metastases that remained clinically confined to the skeleton $(P<.001) .{ }^{47}$

Recent research has shown that bone metastases are strongly associated with ER-positive but progesterone receptor (PR)-negative breast carcinomas. ${ }^{48}$ Expression of CXCR4, a receptor for stromal cellderived factor- 1 in breast cancer, has also been associated with a higher rate of bone metastasis. ${ }^{49}$

A study by Lipton et al. $^{50}$ found that higher pretreatment serum $\beta$-CTx, which promotes the growth of breast cancer cells, appears to predict shorter recurrence-free survival for patients with bone-only metastasis. Other known prognostic indicators for bone metastasis in breast cancer include the production of parathyroid hormone-related peptide by the tumor and the presence of a well-differentiated primary tumor. ${ }^{13}$ However, these predictors of bone metastasis have not been considered very powerful in breast cancer.

Factors identified with risk for bone metastases in prostate cancer patients include current ADT or other definitive therapy, rising prostate-specific antigen (PSA), extent of disease on bone scan, serum alkaline and acid phosphatase, a primary Gleason score of 8 to 10, and clinical stage T3-T4; although some studies have found digital rectal examination finding, Gleason score, and age unhelpful in predicting which patients might experience progression to bone metastasis. ${ }^{51-55}$

Genetic Indicators of Bone Metastasis Risk: The latest avenue of research into predicting and preventing metastases is the identification of genes asso- ciated with metastatic disease. Genetic markers are being explored to predict sites of metastasis in cancer patients, and several genes have been identified with a high likelihood of metastasis to bone. ${ }^{56-59}$

Several genetic predictors of bone metastasis in breast cancer have been identified. ${ }^{60}$ In a mouse model designed to human breast cancer cell lines, 4 proteins coded by a 122-gene signature were found to enhance bone metastasis. ${ }^{61}$ These include chemokine receptor CXCR4, matrix metalloproteinase-1 (MMP-1), connective tissue-derived growth factor, and interleukin-11, which affect tumor cell migration, angiogenesis, and osteolysis. ${ }^{12,61}$ Animal models also link fibroblast growth factor receptor (FGFr) and osteopontin to an increased risk for metastasis. ${ }^{12}$ A study of 107 primary breast tumors identified a 31-gene signature that predicted relapse to bone with a $79.3 \%$ positive predictive value. ${ }^{61}$ The most differentially expressed gene in the signature was the trefoil protein encoding gene, TFF1; the most evident mechanism encoded was cellular adhesion (which helps circulating cancer cells cleave to bone), and the predominant signaling pathway was FGFr-mitogen-activated protein kinase (MAPK). ${ }^{56}$

Most prostate cancers show androgen-dependent growth, so many analyses have focused on the polymorphisms of genes involved in biosynthesis and metabolism of steroids and androgens. A study by Kumazawa et al. $^{62}$ reported that the IGF-I (CA) repeat and CYP19 (TTTA) repeat polymorphisms may be novel predictors in prostate cancer patients with bone metastasis at diagnosis.

\section{Monitoring Metastases With Biochemical Markers}

Although markers of bone turnover are not definitive in diagnosing skeletal metastases, they can be very useful in monitoring patients with known primary cancers for metastases to bone. Biomarkers such as urine NTx, procollagen propeptides of type 1 collagen (PINP), carboxy-terminal telopeptide of type I collagen (ICTP), serum MMP-1, bone sialoprotein, and osteopontin have been studied for identifying bone metastases in various primary tumors.

The most recent NCCN Clinical Practice Guidelines in Oncology: Breast Cancer (to view the most recent version of these guidelines, visit the NCCN Web site at www.nccn.org) do not specify clinical or genetic biomarkers for the risk of bone metastasis when the breast is the primary site of cancer; several 
Lipton et al.

studies have suggested a potential role for biomarkers in cancer prognosis. ${ }^{6}$

Elevated levels of bone turnover markers like urine NTx indicate excessive bone resorption and are predictive of SREs, progression of bone lesions, and death. ${ }^{63-65}$ Despite bisphosphonate use, some breast cancer patients may continue to have elevated NTx levels (moderate [50-99 nmol/mmol], to high [> 100 $\mathrm{nmol} / \mathrm{mmol}$ ] creatinine), which increases the risk for adverse outcomes compared with patients who have low NTx levels ( $<50 \mathrm{nmol} / \mathrm{mmol}$ creatinine) while on intravenous bisphosphonates. ${ }^{66}$

PSA is tracked to monitor disease progression in patients with prostate cancer. Bone scans are generally unnecessary in asymptomatic prostate cancer patients with a PSA level of $20 \mathrm{ng} / \mathrm{mL}$ or less, ${ }^{52}$ because rising PSA levels can indicate distant metastases before they are detectable on scans. ${ }^{67}$ However, diagnostic imaging is indicated for high-risk patients, because studies show that bone metastases remain underdiagnosed in these patients. ${ }^{51}$

Alkaline phosphatase and TRAP are markers of osteoblast and osteoclast activity, respectively. TRAP has been found to be significantly higher in breast cancer patients with bone metastases than in those without. ${ }^{68,69} \mathrm{Ozu}$ et al. ${ }^{70}$ found serum TRAP to be a useful predictor of bone metastases in prostate cancer, and that a combination of TRAP, alkaline phosphatase, and PSA can obviate a bone scan in $70 \%$ of cases.

Serial measurements of PINP have also shown usefulness in detecting bone metastases in prostate cancer. ${ }^{71}$ Another recent study showed that although ICTP is not better at detecting bone metastases than PSA or alkaline phosphatase, it may help identify whether bone metastases are present when the other serum tests are inconclusive. ${ }^{72}$ ICTP and MMP-1 are also being studied as prognostic markers in some breast cancer patients, because NTx can be affected by bisphosphonate treatment. ${ }^{73}$

Expression of Dickkopf-1 (Dkk-1), which appears to play a major role in the regulation of bone metabolism, increases early in prostate cancer development and decreases during progression, particularly in advanced bone metastases. ${ }^{74}$ In breast cancer patients, serum Dkk-1 is also significantly increased in women presenting with bone metastases. ${ }^{75}$ However, serum measurements of Dkk-1 cannot be used alone to diagnose bone metastases from breast cancer.
Although bone sialoprotein and osteopontin have been shown to be predictive of bone metastases in breast and prostate carcinoma, they are still under investigation in other cancers, such as non-small cell lung carcinoma. ${ }^{76,77}$

\section{Targeted Therapies for Cancer-Related Effects on Bone}

Insights into the pathophysiology of bone loss have led to the development of current and emerging drug therapies targeted to specific molecular pathways. ${ }^{78}$ These agents are useful for both treatment- and metastasis-induced disruptions in bone metabolism. Drug therapies fall into 2 broad categories: antiresorptive and anabolic agents, as summarized in Table $2 .{ }^{78-86}$ Other measures vital to patient comfort include surgical stabilization of bone and pain management through analgesics, radiopharmaceuticals, and palliative chemotherapy. ${ }^{1}$

\section{Bisphosphonates}

The best known of the antiresorptive therapies are bisphosphonates, which cause apoptosis of the osteoclast to inhibit bone resorption. Two classes of bisphosphonates have been determined: nonnitrogen-containing agents (e.g., clodronate) that act by way of toxic metabolites, and nitrogen-containing agents (e.g., alendronate, risedronate) that inhibit the enzyme farnesyl pyrophosphate synthase, causing a breakdown of the osteoclast cytoskeleton. ${ }^{79} \mathrm{~A}$ task force from NCCN and guidelines from ASCO currently recommend bisphosphonates for both bone metastases and treatment-related bone loss in breast and prostate cancer; ${ }^{1,5,6}$ these drugs are also recommended for treating bone lesions in multiple myeloma. ${ }^{7}$ Vitamin D and supplemental calcium provide adjunctive support of bone health in cancer patients taking bisphosphonates. ${ }^{5,6}$

The results of trials that assessed bisphosphonates in breast cancer have been somewhat inconsistent. In a meta-analysis of 9 studies that included 2189 women with advanced breast cancer and existing bone metastases, bisphosphonates reduced the risk of developing SREs by $17 \%$ (relative risk [RR], $0.83 ; 95 \% \mathrm{CI}$, $0.78-0.89 ; P<.001)$. This effect was more modest but still significant if episodes of hypercalcemia were excluded (10 studies, 2656 women; RR, 0.85; 95\% CI, 0.79-0.91; $P=.0001)$. Overall, intravenous bisphosphonates reduced the risk of developing SREs by $17 \%$ 


\begin{tabular}{|c|c|c|c|}
\hline Drug Class & Specific Agents & Mode of Action & Adverse Effects \\
\hline \multirow[t]{4}{*}{ Bisphosphonate } & \multirow{3}{*}{$\begin{array}{l}\text { Nitrogenous: } \\
\text { Alendronate } \\
\text { Ibandronate*} \\
\text { Neridronate } \\
\text { Olapadronate } \\
\text { Pamidronate } \\
\text { Risedronate } \\
\text { Zoledronic acid** }\end{array}$} & \multirow{2}{*}{$\begin{array}{l}\text { FPPS blockade to induce } \\
\text { apoptosis of the osteoclast } \\
\text { and thereby slow bone } \\
\text { resorption }\end{array}$} & Osteonecrosis of the jaw \\
\hline & & & $\begin{array}{l}\text { Upper gastrointestinal adverse events } \\
\text { (related to oral drug delivery) }\end{array}$ \\
\hline & & \multirow[t]{2}{*}{$\begin{array}{l}\text { Metabolites toxic to } \\
\text { osteoclasts }\end{array}$} & \\
\hline & $\begin{array}{l}\text { Non-nitrogenous: } \\
\text { Clodronate } \\
\text { Etidronate* } \\
\text { Tiludronate* }\end{array}$ & & \\
\hline SERM & Raloxifene ${ }^{\star \S}$ & $\begin{array}{l}\text { Mix of agonism/antagonism } \\
\text { at estrogen receptors to } \\
\text { modulate estrogen levels } \\
\text { and thereby suppress bone } \\
\text { resorption }\end{array}$ & $\begin{array}{l}\text { Venous thromboembolism } \\
\text { Stroke } \\
\text { Hot flashes } \\
\text { Leg cramps }\end{array}$ \\
\hline $\begin{array}{l}\text { Polypeptide } \\
\text { hormone }\end{array}$ & Calcitonin* & $\begin{array}{l}\text { Induces quiescence and } \\
\text { retraction of osteoclasts to } \\
\text { slow bone resorption }\end{array}$ & $\begin{array}{l}\text { Potential for allergic reactions } \\
\text { Nasal symptoms (related to nasal drug } \\
\text { delivery) }\end{array}$ \\
\hline Mineral salt & Strontium ranelate & $\begin{array}{l}\text { Osteoblast/collagen } \\
\text { stimulation (bone formation); } \\
\text { osteoclast inhibition } \\
\text { (inhibition of bone resorption) }\end{array}$ & $\begin{array}{l}\text { Gastrointestinal adverse events } \\
\text { Dermatitis/eczema }\end{array}$ \\
\hline $\begin{array}{l}\text { Monoclonal } \\
\text { antibody }\end{array}$ & Denosumab & $\begin{array}{l}\text { Binds to RANKL to suppress } \\
\text { osteoclast formation }\end{array}$ & $\begin{array}{l}\text { Arthralgia } \\
\text { Gastrointestinal adverse events }\end{array}$ \\
\hline $\begin{array}{l}\text { Parathyroid } \\
\text { hormone }\end{array}$ & Teriparatide* & $\begin{array}{l}\text { Mimics osteoblast-stimulating } \\
\text { effect of endogenous } \\
\text { parathyroid hormone to } \\
\text { increase bone formation }\end{array}$ & $\begin{array}{l}\text { Osteosarcoma (animal models) } \\
\text { Transient hypercalcemia } \\
\text { Muscle spasm }\end{array}$ \\
\hline
\end{tabular}

Abbreviations: FPPS, farnesylpyrophosphate synthase; RANKL, receptor activator of nuclear factor kappa B ligand; SERM, selective estrogen receptor modulator. *Approved by the US Food \& Drug Administration.

'Specifically approved for the management of hypercalcemia of malignancy and osteolytic bone metastasis. ‡Specifically approved for the management of hypercalcemia of malignancy, multiple myeloma, and bone metastasis of solid tumors.

${ }^{\S}$ Also indicated for reducing the risk of invasive breast cancer in select postmenopausal women; other SERMS (e.g., tamoxifen). Data from references 78-86.

(95\% CI, 0.78-0.89) compared with oral bisphosphonates, which reduced this risk by $16 \%$ (95\% CI, 0.76-0.93; Table 3). ${ }^{87}$

Oral clodronate has been shown to significantly improve 5-year skeletal relapse-free survival when used as supplementary adjuvant therapy for patients undergoing standard treatment for primary operable breast cancer ${ }^{88}$ The addition of zoledronic acid to adjuvant endocrine therapy has been shown to improve disease-free survival in premenopausal patients with estrogen-responsive early breast cancer, ${ }^{89}$ whereas another study indicated that when zoledronic acid is added to neoadjuvant chemotherapy in breast cancer treatment, it may have direct antitumor effects. ${ }^{90}$

However, not all studies favored bisphosphonates. Ten-year follow-up results of an adjuvant clodronate trial in patients with primary breast cancer revealed that bone metastases were detected at the same frequency in the clodronate and control groups at year 10, while the frequency of nonskeletal recurrences (visceral and local) was significantly higher and disease-free survival significantly lower in the clodronate group. ${ }^{91}$ This was particularly notable in ER-negative patients ( $25 \%$ vs. $58 \%$; $=.004)$. 
Lipton et al.

\begin{tabular}{|c|c|c|}
\hline $\begin{array}{l}\text { Bisphosphonate } \\
\text { (Dose, Route of Administration) }\end{array}$ & Reduction in Risk of SRE & Relative Risk $(95 \% \mathrm{Cl})$ \\
\hline Zoledronic acid, 4 mg IV & $41 \%$ & $0.59(0.42-0.82)$ \\
\hline Pamidronate, 90 mg IV & $23 \%$ & $0.77(0.69-0.87)$ \\
\hline Ibandronate, 6 mg IV & $18 \%$ & $0.82(0.67-1.00)$ \\
\hline Ibandronate, 50 mg PO & $14 \%$ & $0.86(0.73-1.02)$ \\
\hline Clodronate, 1600 mg PO & $16 \%$ & $0.84(0.72-0.98)$ \\
\hline
\end{tabular}

Abbreviations: IV, intravenous; PO, by mouth; SRE, skeletal-related event.

Data from Pavlakis N, Schmidt R, Stockler M. Bisphosphonates for breast cancer. Cochrane Database Syst Rev 2005;CD003474.

The use of bisphosphonates is currently a palliative measure, because they have not been consistently shown to improve survival or prevent bone metastasis. ${ }^{5,6}$ However, emerging evidence from preclinical studies in a variety of tumor types suggests that bisphosphonates, alone or in combination with other chemotherapies, may reduce tumor burden in bone and soft tissue, inhibit angiogenesis, prevent tumor cell invasion and adhesion to bone, and induce tumor cell apoptosis..$^{92-96}$

Bisphosphonate use can result in 2 significant adverse events: osteonecrosis of the jaw (ONJ) and renal impairment. The current definition of ONJ is the presence of exposed bone in the mouth that fails to heal after appropriate intervention over a period of 6 to 8 weeks. ${ }^{97}$ Tooth extraction is a risk factor in patients treated with zoledronic acid, pamidronate, or a combination of these agents for the management of myeloma, as well as breast or prostate cancers. The prevalence of $\mathrm{ONJ}$ is approximately $5 \%$ in multiple myeloma patients treated with bisphosphonates, though it may be decreasing with better dental prophylaxis. ${ }^{97,98}$

Active resorption has been seen in $\mathrm{ONJ}$ bone lesions, probably stimulated by infection of the immediate area. The result of this resorption is the local release of bisphosphonates at high concentrations. Management of this side effect focuses on prevention and treatment of infection; the role of surgery remains unclear. Minor debridement, sequestrectomy, and combining bone resection with autologous plateletrich plasma have also been used to manage ONJ. ${ }^{98}$

Another potential side effect of intravenous bisphosphonate treatment is renal deterioration. ${ }^{99}$ In cancer patients, this is precipitated by a variety of factors, including advancing or progressive cancer, chemotherapy, administration of concomitant nephrotoxic medications, and comorbidities, such as severe dehydration, chronic renal failure, hypertension, or diabetes. ${ }^{100}$ Although it is prudent to monitor the renal function of any patient on intravenous bisphosphonates (specific guidelines for renal monitoring are included in product labeling), the patient's individual medical situation must also be considered. An analysis of patients who received intravenous bisphosphonates showed the rate of renal deterioration to be $9 \%$ to $15 \%$ for zoledronic acid and $8 \%$ to $12 \%$ for pamidronate. However, the rate of renal deterioration among patients in the placebo groups of the same trials was $7 \%$ to $12 \%,{ }^{101}$ substantiating the inherent increased risk of renal deterioration in patients with advanced or metastatic cancer.

When used at recommended dosages, intravenous bisphosphonates can benefit patients with bone metastases, and have an established safety profile. Regular monitoring of renal function is recommended when bisphosphonates are used for patients with metastatic cancer. Ensuring adequate hydration and discontinuing treatment if renal function deteriorates are also important. ${ }^{102,103}$

\section{Other Antiresorptive Therapies}

Other currently available antiresorptive drugs include selective estrogen receptor modulators (SERMs), such as raloxifene, ${ }^{78}$ and calcitonin, an inhibitor of osteoclast function. ${ }^{80}$ Therapies with antiresorptive properties in clinical trials for bone metastases include RANKL inhibitors and strontium ranelate.

Osteoclast formation, function, and survival require RANKL activity. ${ }^{104}$ Experts hypothesize that through RANKL, tumor cells induce osteoclast activation, which then mediates bone resorption and release of growth factors, resulting in a cycle of bone 
destruction and tumor proliferation. ${ }^{2}$ Denosumab is an investigational monoclonal antibody directed against RANKL; it binds to RANKL and blocks the ligand from stimulating osteoclast formation. ${ }^{78}$

A preliminary study of denosumab in postmenopausal women showed profound reductions in urine NTx maintained over 6 months with a single subcutaneous dose. ${ }^{105}$ A phase II study found that 12 months of treatment with various regimens including denosumab increased BMD in postmenopausal women at the lumbar spine by $3.0 \%$ to $6.7 \%$ across the regimens, compared with an increase of $4.6 \%$ with alendronate and a loss of $0.8 \%$ with placebo. ${ }^{81}$ Percentage increases at the hip and distal radius were also higher with denosumab than with alendronate or placebo. Additional clinical trials are in progress to evaluate denosumab for preventing and treating bone metastasis in prostate cancer. ${ }^{5}$

Clinical trials evaluating denosumab for use in osteoporosis and bone metastases are also in progress. Fizazi et al. ${ }^{106}$ recently reported that, among patients with elevated NTx despite ongoing intravenous bisphosphonate therapy, denosumab normalized NTx levels more frequently than the continuation of intravenous bisphosphonates. ${ }^{106}$

Cathepsin K plays a key role in osteoclastmediated bone resorption, and is therefore also a therapeutic target for the treatment of diseases associated with increased bone loss. Preclinical studies show that cathepsin $\mathrm{K}$ inhibitors reduce breast cancer-induced osteolysis and skeletal tumor burden. These findings support a promising future for the use of cathepsin $\mathrm{K}$ inhibitors, alone or in combination with other antiresorptive drugs, in treating patients with bone metastasis. ${ }^{107}$

\section{Anabolic Agents}

Strontium ranelate has effects on both the resorption and formation of bone. It appears to enhance the replication of osteoblast precursor cells and increase collagen synthesis in osteoblasts, while also inhibiting differentiation and activity of osteoclasts. ${ }^{82}$ The drug has shown a risk reduction of $41 \%$ over 3 years for new vertebral fractures in postmenopausal women with osteoporosis $(\mathrm{N}=1649) .{ }^{83} \mathrm{~A}$ larger study $(\mathrm{N}=5091)$ found that strontium ranelate reduced nonvertebral fractures by $16 \%$ over 3 years in a similar patient population. ${ }^{84}$

An anabolic agent, parathyroid hormone (teriparatide), is indicated for osteoporosis treatment. ${ }^{78}$ This drug mimics the osteoblast-stimulating effects of en- dogenous parathyroid hormone. However, teriparatide increases the risk for osteosarcoma in animals and also produces transient hypercalcemia, so its use in cancer patients may not be advisable. ${ }^{85}$ Other areas of investigation in clinical trials include Src tyrosine kinase inhibitors and agents targeting integrins.

\section{Radiopharmaceuticals}

Radiation therapy reduces tumor size, decreases osteolysis, and decreases the skeletal tumor burden. ${ }^{108}$ Radiopharmaceuticals were developed as bonetargeted therapy to provide systemic treatment of osseous lesions. Three radiopharmaceuticals are currently available in the United States: phosphorus, strontium, and samarium, ${ }^{109}$ which are used in a palliative role. However, a limitation to currently available radiopharmaceuticals is that significant, prolonged bone marrow suppression can follow treatment, precluding further systemic treatment with myelosuppressive agents in some patients. ${ }^{110}$

\section{Management of Bone Metastases in Multiple Myeloma}

Multiple myeloma is characterized by the proliferation of plasma cell clones derived from B cells. ${ }^{111,112}$ These clones proliferate within the bone marrow, which is a fertile microenvironment containing numerous growth factors released during normal bone remodeling. They colonize as tumor cells, proliferating and releasing their own growth factors that promote bone resorption. The result is skeletal destruction that manifests as bone pain and fractures. As many as 90\% of multiple myeloma patients develop bone lesions. ${ }^{113}$

Lytic bone disease in multiple myeloma is different from lytic bone metastases in other malignancies in that after the tumor burden exceeds $50 \%$ in a local area, osteoblast activity is either suppressed or absent. The origin of this severe imbalance between increased osteoclastic bone resorption and decreased bone formation has been a topic of intensive investigation for many years. ${ }^{113}$

\section{Diagnostic Signs}

A multiple myeloma diagnosis depends on identification of abnormal monoclonal plasma cells in the bone marrow, $\mathrm{M}$-protein in the serum or urine, osteolytic lesions, and a clinical picture consistent with the disease. In a review of 1027 newly diagnosed multiple myeloma patients, the bone marrow con- 
Lipton et al.

tained $10 \%$ or more plasma cells in $96 \%$ of patients. Conventional radiographic evidence showed an abnormality in $79 \%$ of patients at diagnosis. Other radiographic findings in these patients are presented in Table $4 .{ }^{112}$ In one review, ${ }^{111}$ bone pain existed at diagnosis in $58 \%$ of patients (mild in $29 \%$, moderate in $20 \%$, and severe [grade 3 or 4 ] in $9 \%$ ).

Although the gold standard for imaging myeloma bone lesions is bone survey, plain radiographs are relatively insensitive for imaging myeloma and can only show lytic disease when $30 \%$ of the trabecular bone has been lost. ${ }^{114}$ For measuring extent of disease, ${ }^{99 \mathrm{~m}} \mathrm{Tc}$ bone scanning is inferior to conventional radiography and should be avoided, because bone scans underestimate the extent of bone involvement in patients with myeloma. ${ }^{14,115}$ Large lytic lesions may not be evident on radionuclide scans, because osteoblastic activity does not occur, and CT is valuable for patients who have bone pain but show no abnormalities on radiography. PET scans have been used to detect bone lesions in patients with myeloma, are more sensitive than plain radiographs, and have the same sensitivity as MRI for detecting bone disease in the spine and pelvis. ${ }^{114}$

\section{Treatment and Prevention of Bone Metastases}

Several strategies are used in the treatment and prevention of bone metastases in multiple myeloma, including radiotherapy, surgery, and pharmacotherapy. Radiotherapy: Radiotherapy is used to treat painful local lesions, helping to reduce symptoms and minimize complications; however, it is not curative. Radiation is an effective method of reducing bone pain in vertebral

\begin{tabular}{|lc|}
\hline Table 4 & $\begin{array}{l}\text { Radiographic Findings in Patients } \\
\text { with Multiple Myeloma* }\end{array}$ \\
\hline Finding & \% of Patients \\
\hline Lytic lesions & 66 \\
Pathologic fracture & 26 \\
Compression fracture & 22 \\
Osteoporosis & 23 \\
Osteosclerosis & 0.5 \\
Negative & 21 \\
\hline
\end{tabular}

$* \mathrm{~N}=1005$.

${ }^{\dagger}$ Total surpasses $100 \%$ because many patients had more than 1 abnormality.

Data from Lipton A. Pathophysiology of bone metastases: how this knowledge may lead to therapeutic intervention. J Support Oncol 2004;2:205-220. and nonvertebral fractures and reducing extramedullary formations. In one study of patients with multiple myeloma, radiotherapy was administered in $92 \%$ of patients with vertebral fractures, $91 \%$ with nonvertebral fractures, and $94 \%$ with extramedullary tumor formations. ${ }^{116}$ In $90 \%$ of the patients, complete or partial pain palliation was achieved, and resolution of neurologic symptoms was seen in 59\%. Median survival of patients receiving radiotherapy was 32 versus 33 months for patients who did not receive it $(P>.05)$; survival rates were not influenced by this treatment.

Percutaneous Vertebroplasty: A minimally invasive method of treatment, percutaneous vertebroplasty (PV), involves injection of polymethyl methacrylate (PMMA) into painful fractures. Fractured bone fragments can be stabilized and strengthened using PMMA, substantially improving pain. A study comparing $\mathrm{PV}$ alone or in combination with radiofrequency ablation found PV to be safe and effective for the palliative management of painful extraspinal bone metastases (acetabulum, femur, humerus, scapula, and iliac bone) when used alone for small lesions or combined with radiofrequency in larger lesions. ${ }^{117}$

In another recent study, analgesic efficacy was achieved in all patients, suggesting that PV is safe and effective for pain control in multiple myeloma of the cervical spine. Nevertheless, the damaging impact of the disease on bone quality should prompt careful radiologic follow-up after PV, because of the risk for spinal instability. ${ }^{118}$

Kyphoplasty: A more recent modification of vertebroplasty is percutaneous balloon kyphoplasty, whereby inflation of a balloon before PMMA injection can restore vertebral height and reduce kyphotic deformity in addition to stabilizing the fractured vertebral body. ${ }^{119}$

A novel kyphoplasty procedure that gives uniform bone expansion in treatment of vertebrae with heterogeneous bone structure is called controlled segmental balloon kyphoplasty. ${ }^{120}$ The procedure consists of 2 parts. In the first part, the balloon remains partially in its introducer trocar to inflate only the distal segment of the balloon in an area of stronger bone, which provides high mechanical resistance. This segmental inflation creates a cavity that will allow initiation of fracture reduction in the stronger bone area. In the second part of the procedure, the emerging segment is deflated and the balloon is advanced until it emerges completely from the introducer tro- 
car, after which the balloon is completely inflated in the vertebral body. In a small study of 5 patients, 2 of whom had multiple myeloma, all patients were painfree at 1 month after the procedure. ${ }^{120}$

Pharmacotherapy: Pharmacotherapy, specifically chemotherapy, is the treatment of choice in multiple myeloma. However, no curative options currently exist. Therefore, the treatment strategy is to reduce symptoms and minimize complications.

Bisphosphonates: Bisphosphonates are powerful inhibitors of osteoclast activity that have shown some efficacy in the treatment of bone metastases. ${ }^{121}$ Originally, pamidronate was used to treat patients with myeloma-related bone complications. One study showed that monthly infusions of pamidronate as an adjunct to chemotherapy, given over 21 monthly cycles, were superior to chemotherapy alone in reducing SREs in patients with stage III multiple myeloma. ${ }^{122}$

A later comparative study showed that $4 \mathrm{mg}$ of zoledronic acid given by way of 15-minute infusion administered every 3 to 4 weeks for 12 months was as effective and well tolerated as $90 \mathrm{mg}$ of pamidronate given by way of 2-hour infusion for treating osteolytic and mixed bone metastatic lesions in patients with multiple myeloma. ${ }^{123}$

One study of multiple myeloma patients on zoledronic acid puts the frequency of ONJ, a potential complication associated with bisphosphonate use, at $15 \%$, with the mean drug exposure time at 34 months. However, other studies have reported lower frequencies. For example, manufacturer-sponsored epidemiologic studies reported the estimated incidences of ONJ at $0.1 \%$ to $1.8 \%$; one study reported a $3 \%$ incidence; and the International Myeloma Foundation set the rate at $5 \%$ to $10 \% .^{124,125}$ The clinical course of multiple myeloma was not affected when bisphosphonates were discontinued in a patient with $\mathrm{ONJ}$, although the recurrence of bone pain and progression of metastases or osteolytic lesions can result. ${ }^{126}$

Agents in Development: Impaired bone formation contributes to the lack of bone healing in multiple myeloma. Agents with bone anabolic properties are needed to reverse or retard bone deficit.

Denosumab: In a multicenter study to determine the safety and efficacy of denosumab in patients with multiple myeloma or breast cancer complicated by radiologically confirmed bone lesions, patients received a single dose of either denosumab $(0.1,0.3,1.0$, or 3.0 $\mathrm{mg} / \mathrm{kg}$ subcutaneously) or pamidronate (90 mg in- travenously). ${ }^{127}$ The antiresorptive effect was evaluated by measuring changes in urinary and serum NTx levels. After a single dose of denosumab, NTx levels decreased within 24 hours. They remained decreased through 84 days at the higher denosumab doses. Pamidronate also decreased bone turnover, but the effect diminished progressively through follow-up. In an open-label phase II trial of denosumab in the treatment of multiple myeloma, bone resorption markers decreased $72 \%$ in patients experiencing relapse and $52 \%$ in patients experiencing plateau, although no apparent effect on tumor burden as measured by monoclonal protein was seen. ${ }^{128}$

Dkk-1 Inhibition: Dkk-1, a soluble inhibitor of Wnt signaling secreted by multiple myeloma cells, contributes to osteolytic bone disease by reducing osteoblast differentiation. ${ }^{129}$ In fact, Dkk-1 levels in the blood and bone marrow correlate with the extent of bone disease. ${ }^{130}$ Blocking Dkk-1 in myelomatous bones in animal models of myeloma reduces osteolytic bone resorption, increases bone formation, and helps control the progression of multiple myeloma. ${ }^{129}$

In a murine model, mice were engrafted with primary multiple myeloma cells expressing varying levels of Dkk-1 from 11 patients and treated with control and Dkk-1-neutralizing antibodies for 4 to 6 weeks. BMD significantly increased from pretreatment levels $(P<.001)$. The bone anabolic effect of anti-Dkk-1 was associated with reduced multiple myeloma burden $(P<.04)$. Anti-Dkk-1 also boosted $\mathrm{BMD}$ of the implanted bone and murine femur in nonmyelomatous mice, suggesting that Dkk-1 is an important regulator of bone remodeling in adults. Clinical studies are in development. ${ }^{129}$

Bortezomib: Bortezomib, a proteasome inhibitor with antitumor efficacy in myeloma patients, has been shown to enhance new bone formation in mouse skull cultures, an effect that was inhibited by Dkk-1 (discussed previously). ${ }^{131}$ Bortezomib inhibited Dkk-1 expression in calvariae and bone marrowderived stromal cells, suggesting a novel mechanism through which bortezomib exerts its effects in bone.

Other research has shown that selectively inhibiting the osteoblast proteasome regulates osteoblast differentiation and bone formation and that inhibition of specific components of this system may be therapeutically valuable in diseases of bone loss. ${ }^{132}$ The stimulatory effect of bortezomib on bone nodule formation was also shown in osteoblast progeni- 


\section{Lipton et al.}

tors. ${ }^{133}$ These in vitro observations were confirmed in vivo by the detection of a significant increase in the number of osteoblastic cells in bone tissue and in multiple myeloma patients who showed a response to bortezomib. Bortezomib also inhibits human osteoclastogenesis. ${ }^{134}$ These in vitro and in vivo observations maintain the hypothesis that a direct stimulatory effect on the bone formation process could occur during bortezomib treatment.

Lenalidomide: Immunomodulatory drugs such as lenalidomide that are active against myeloma also block the activity of bone-resorbing osteoclasts. ${ }^{135}$ Lenalidomide affects osteoclastogenesis by inducing osteoclast precursors toward granulocyte lineage. ${ }^{136}$ As with bortezomib, lenalidomide inhibits osteoclastogenesis. A comparison of their mechanisms of action is presented in Table $5 .{ }^{136}$ Both agents specifically target key factors in osteoclastogenesis and may ultimately control the formation of osteoclasts when used in combination.

A variety of means to curb the impact of bone metastases continue to be explored. Ultimately, such treatment strategies may include a combination of radiotherapy, vertebroplasty, kyphoplasty, and pharmacotherapy. The bisphosphonates are useful medications in myeloma-derived bone complications if used according to manufacturer recommendations. The future also holds the promise of newer agents, such as denosumab and Dkk-1 inhibitors, that can provide more options for clinicians.

\section{Management of Bone Metastases in Breast Cancer}

Between $30 \%$ and $85 \%$ of patients with breast cancer develop bone metastases at some point during the disease. ${ }^{115,137}$ Bone also represents the first site of metastasis for $26 \%$ to $50 \%$ of patients with metastatic breast cancer. ${ }^{138}$ Skeletal metastases can result in bone pain, fractures, spinal cord compression, and hypercalcemia.

Up to half of bone metastases from breast cancer show osteolytic changes, although osteoblastic and mixed lesions are often present as well. ${ }^{30}$ Bisphosphonate use over the past decade has decreased the relative incidence of lytic lesions, with a corresponding increase in the percentage of mixed lesions. ${ }^{45}$

Survival rates for patients with metastases vary considerably; the median survival time is 2 to 3 years. However, numerous factors can aid in predict- ing objective response rate, time to progression, and overall survival, including:

- Disease-free interval of less than 2 years ${ }^{139}$

- Performance status, ${ }^{140}$ because good performance status has been shown increase survival; alleviation of factors such as bone pain through adequate pain control improves performance status by preventing incapacitation and sleep interference sleep and increasing a patient's overall quality of life

- Site of metastasis ${ }^{141}$

- Visceral; patients who have liver metastasis have been shown to do well compared with those who do not ${ }^{140}$

- Bone; studies show worse survival for patients with bone as the dominant site of metastasis than for those with soft tissue metastasis only ${ }^{142}$

- Soft tissue

- Number of metastatic sites; ${ }^{140,141}$ although the actual extent of bony disease is difficult to determine, the number of metastatic sites on bone scans has been shown to correlate with survival ${ }^{143}$

- Hormone receptor status ${ }^{141}$

- HER2/neu status; ${ }^{144}$ several studies have reported that patients who have an overexpression of HER2/ neu in tumor tissue or elevated serum levels have a shorter time to progression and overall survival Breast cancer patients with ER-positive tumors have an increased risk of bone metastasis. ${ }^{48,145,146} \mathrm{~A}$ recent study by Wei et $a l .{ }^{48}$ found that bone metastasis was significantly more likely when breast tumors were ER-positive/PR-negative $(P<.001)$. Breast cancers with bone metastasis were more likely to be ER-positive (85\% of cases) than those without (59\% of cases; $P<.05)$. However, the study also found that breast cancers with bone metastasis were also more likely to be androgen receptor-positive (95\% of cases) than those without ( $74 \%$ of cases; $P<.05) .{ }^{48}$

\section{ASCO Guidelines: 2003 Update}

Since 2000, 2 randomized clinical trials using oral clodronate as an adjuvant therapy were reported. Perhaps as a result, major clinical trial groups in the United States, Canada, and Europe have shifted bisphosphonate use to the adjuvant setting, and in 2003, ASCO updated the 2000 guidelines on bisphosphonate use in breast cancer. Trials using bisphosphonates to combat treatment-associated bone loss, such as that caused by AIs or chemother- 
apy, have also been reported. No major randomized controlled trials in the metastatic setting were begun before the updated ASCO guidelines were released. However, since then, several different trials have started or are expected to start.

For each of the guidelines, the patient's general performance status and overall prognosis should also be taken into consideration. ${ }^{147}$ For breast cancer patients who have evidence of bone destruction on plain radiographs, the 2003 ASCO guidelines recommend the following: ${ }^{147}$

Intravenous pamidronate, $90 \mathrm{mg}$, delivered over 2 hours or zoledronic acid, $4 \mathrm{mg}$, over 15 minutes every 3 to 4 weeks. There is insufficient evidence supporting the efficacy of one bisphosphonate over the other.

In addition, the guidelines state that, for women with abnormal bone scan results and CT or MRI results showing bone destruction but negative results on plain radiography, starting bisphosphonates is reasonable based on the findings in women with lytic or mixed lytic/blastic changes on plain radiographs. On the other hand, the guidelines do not recommend starting bisphosphonates in women with only abnormal bone scan results without evidence of bone destruction on radiographs, CT scans, or MRI. ${ }^{147}$

Other important updates in the ASCO guidelines focused on the safety and adverse effects of bisphosphonates, including: ${ }^{147}$

- In patients with pre-existing renal disease and serum creatinine less than $3.0 \mathrm{mg} / \mathrm{dL}(265 \mu \mathrm{mol} / \mathrm{L})$, no change in dosage, infusion time, or interval of pamidronate or zoledronic acid is required. However, use of these bisphosphonates among patients with worse function has been minimally assessed.

- Infusion times less than 2 hours with pamidronate or less than 15 minutes with zoledronic acid should be avoided.

- Serum creatinine should be monitored before each dose of pamidronate or zoledronic acid, in accordance with FDA-approved labeling. Serum calcium, electrolytes, phosphate, magnesium, and hematocrit or hemoglobin should also be monitored regularly, but no evidence is available on which to base recommendations for time intervals.

Bisphosphonates also have a role in controlling pain caused by bone metastases. The ASCO guidelines recommend that, among other therapeu-

\begin{tabular}{|c|c|c|c|}
\hline \multirow[t]{2}{*}{ Table 5} & \multicolumn{3}{|c|}{$\begin{array}{l}\text { Enhanced Osteoclast Activation and } \\
\text { Osteoclastogenesis With } \\
\text { Lenalidomide and Bortezomib in } \\
\text { Multiple Myeloma }\end{array}$} \\
\hline & & Lenalidomide & Bortezomib \\
\hline \multirow{2}{*}{\multicolumn{2}{|c|}{ Inhibitory target }} & $\begin{array}{l}\text { PU.1* } \\
\text { (transcription } \\
\text { factor) }\end{array}$ & $\begin{array}{l}\text { Nuclear } \\
\text { factor }^{*}\end{array}$ \\
\hline & & $\begin{array}{l}\text { pERK } \\
\text { (transmembrane } \\
\text { protein kinase) }\end{array}$ & \\
\hline \multicolumn{2}{|c|}{$\begin{array}{l}\text { Impact on cell } \\
\text { invasiveness }\end{array}$} & \multicolumn{2}{|c|}{$\begin{array}{l}\text { Decreases alpha V beta } \\
\text { 3-integrin }{ }^{\dagger}\end{array}$} \\
\hline \multicolumn{2}{|c|}{$\begin{array}{l}\text { Effects on bone } \\
\text { resorption }\end{array}$} & \multicolumn{2}{|c|}{ Decreases TRAP cells $s^{\ddagger}$} \\
\hline \multicolumn{2}{|c|}{ Effects on RANKL } & \multicolumn{2}{|c|}{$\begin{array}{l}\text { Decreases RANKL secretion of } \\
\text { bone marrow stromal cells }\end{array}$} \\
\hline \multicolumn{2}{|c|}{$\begin{array}{l}\text { Effects on } \\
\text { cathepsin } \mathrm{K}^{\S}\end{array}$} & \multicolumn{2}{|c|}{ Downregulates this protease } \\
\hline
\end{tabular}

Abbreviations: RANKL, receptor activator of nuclear factor kappa B; TRAP, tartrate-resistant acid phosphatase. *Inhibition results in a decrease in osteoclastogenesis. ${ }^{+}$Membrane protein that works as a signaling factor in the regulation of osteoclast adhesion and activation.

†Tartrate-resistant acid phosphatase-positive cells that induce the destruction of articular cartilage, an osteoclast marker.

${ }^{\S}$ Essential for resorption of bone collagen matrix. Data from Breitkreutz I, Raab MS, Vallet S, et al. Lenalidomide inhibits osteoclastogenesis, survival factors and bone-remodeling markers in multiple myeloma. Leukemia 2008;22:1925-1932.

tic options, intravenous pamidronate or zoledronic acid may benefit women with bone pain caused by bone metastasis when used concurrently with systemic chemotherapy or hormonal therapy, because bisphosphonates were associated with a modest pain control benefit in clinical trials. ${ }^{147}$

\section{Management of Bone Metastases in Prostate Cancer}

Prostate cancer has a tendency to metastasize that ranges from indolent low-grade to spreading aggressiveness. Bone is the most common site of metastatic disease in prostate cancer, affecting $85 \%$ to $90 \%$ of men with metastases and causing significant morbidity. ${ }^{148,149}$ Approximately $5 \%$ to $10 \%$ of men with newly diagnosed prostate cancer have skeletal metastases. ${ }^{150}$ 
Lipton et al.

\section{Stratification and Staging}

PSA levels, Gleason score at biopsy, disease volume on biopsy, and cancer $\mathrm{T}$ stage at presentation are the most common clinical parameters used for pretreatment risk stratification and prediction of the probability of local recurrence or distant metastatic spread. Based on these clinical parameters, patients are categorized at diagnosis as having low- or highrisk cancer, ${ }^{151}$ aiding in the prediction of the natural history of the disease and the likelihood that it will respond to treatment. ${ }^{152}$

Commonly, patients with low-risk prostate cancer have a low probability of bone involvement. Therefore, bone scans are not routinely recommended for primary staging. ${ }^{36,153}$ Bone scans are mainly used for patients with high-risk cancer (e.g., increased PSA levels), elevated serum alkaline phosphatase levels, bone pain, or equivocal bone lesions on other diagnostic modalities. ${ }^{36,154-156}$ As the disease evolves, patients may experience biochemical progression, local recurrence, or metastatic spread. Approximately $90 \%$ of patients who die of prostate cancer have bone metastases. ${ }^{151,157}$ The extent of metastatic disease from prostate cancer in the skeleton is an independent prognostic factor. ${ }^{158,159}$ Although bone scans remain the most widely used method for evaluating skeletal metastases from prostate cancer, results of published studies raise some doubts as to their efficacy in confirming metastatic bone involvement. ${ }^{36}$

\section{Pathophysiology of Bone Metastasis in Prostate Cancer}

As in breast cancer, bone metastases from prostate cancer show a heterogeneous mixture of osteoblastic and osteolytic lesions. ${ }^{109,160}$ Furthermore, histomorphometric evidence indicates that osteoblastic metastases form on trabecular bone at sites of previous osteoclast resorption, and that this resorption is required for subsequent osteoblastic bone formation, ${ }^{161}$ suggesting that prostate cancer induces bone production through an overall increase in bone remodeling. ${ }^{2}$

Osteoblasts are stimulated by factors secreted by prostate cancer cells to proliferate, differentiate, and secrete growth factors, which are then deposited into the bone matrix and further enrich the local microenvironment of tumor cells. When prostate cancer cells metastasize to bone, they initially induce osteoclastogenesis and bone resorption. RANK, RANKL, and its soluble decoy receptor, osteoprotegerin, are essential regulators of this process. ${ }^{162}$ Eventually, osteoblast-mediated bone mineralization outweighs osteoclast-mediated bone resorption, resulting in a predominance of osteoblastic lesions. This causes more woven bone to form instead of the normal laminar bone, resulting in the complications seen with bone metastases. ${ }^{160}$

\section{Treating Bone Metastases in Prostate Cancer}

Bisphosphonates: Zometa $039^{163}$ was the first trial to show a role for bisphosphonates in the treatment of metastatic prostate cancer. However, other bisphosphonates used at different stages have been disappointing as single agents and in combination with hormones and chemotherapy, and thus currently have no role in standard treatment for prostate cancer. ${ }^{109}$

RANKL-Targeted Agents: Two studies are testing the efficacy of denosumab in prostate cancer patients. One is a phase III noninferiority study comparing denosumab with zoledronic acid in patients with hormone-refractory prostate cancer and bone metastases (NCT00321620). The other is a phase II study testing the effect of denosumab on prolonging bone metastasis-free survival in men with nonmetastatic hormone-refractory prostate cancer (NCT00286091). ${ }^{109}$

Agents Targeting MMP: In prostate cancer, MMPs, specifically MMP-7, have been shown to be involved in invasion and metastasis and to contribute to bone remodeling dysregulation. ${ }^{164}$ One novel drug in this area, BMS-275291, is designed to inhibit a broad spectrum of MMPs. ${ }^{165}$ Recently, a phase II trial of BMS-275291 in men with hormone-refractory prostate cancer and evidence of bone metastasis found no responders according to PSA or measurable disease. Stable disease was noted at 8 weeks in $56 \%$ of patients, but no antitumor activity was seen. Despite this, the role of newer-generation MMPs as combination therapy may warrant further investigation.

Agents Targeting the Endothelin Axis: ET-1, a key component of the endothelin axis, has been identified as having an important role in the pathophysiology of prostate cancer, particularly in the development and progression of osteoblastic bone metastases. Atrasen$\tan$ is a selective, orally bioavailable inhibitor of endothelin type A receptor that is being investigated for hormone-refractory prostate cancer. Notable trials investigating this drug include a randomized phase II trial showing a significant increase in time to progression for patients treated with $10 \mathrm{mg}$ of atrasentan. ${ }^{166}$ 
A combined analysis of the phase II and III trials, which included 1002 patients randomized to receive either $10 \mathrm{mg}$ atrasentan per day or placebo, showed a statistically significant delay in progression ( $\log$ rank $P$ $=.045)$, time to bone pain $(\log \operatorname{rank} P=.025)$, time to PSA progression ( $\log \operatorname{rank} P=.002$ ), and bone alkaline phosphatase progression $(\log$ rank $P<.001)$ compared with placebo. ${ }^{167}$ Another phase III trial is underway investigating the role of atrasentan to delay disease progression in men with nonmetastatic hormone-refractory prostate cancer (M00-244).

\section{Assessing Response to Treatment}

Two possible strategies to improve treatment assessment are the investigation of biochemical markers of bone turnover and improvement of imaging modalities.

\section{Biochemical Markers of Bone Turnover}

In prostate cancer, increased markers of osteolytic activity (urine NTx) and osteoblastic activity (alkaline phosphatase) have been associated with adverse clinical outcomes, including a shorter time to SREs, disease progression, and death. A correlation between baseline values of NTx, alkaline phosphatase, and PSA and the number of bone lesions has also been shown, suggesting that baseline levels relate to tumor burden. ${ }^{66}$ Furthermore, investigation of bone markers in recent studies of bone-targeted therapies has shown suppression of biochemical markers of bone turnover, supporting the potential role of bone turnover markers for assessing the efficacy of novel agents. ${ }^{109}$

\section{Imaging}

Bone scanning is a useful tool to assess skeletal metastases, but lacks the specificity needed to distinguish metastatic lesions and evaluate treatment response. One new area for research is the use of diffusion MRI technology to assess response. A study by Bradley et al. ${ }^{109}$ found that xenografts of PC-3 prostate cancer with confirmed bone metastases showed correlation between changes in functional diffusion mapping (fDM) and changes in bioluminescence imaging in response to docetaxel treatment. Studies are currently underway to assess other imaging protocols, including carbon-11 acetate and FDG-PET in patients with bone-dominant metastatic prostate cancer (NCT00392938); comparison of FDG-PET/CT with conventional imaging to assess treatment response in metastatic prostate cancer (NCT00282906); com- parison of carbon-11-methionine (MET) and FDGPET with standard imaging in men with metastatic prostate cancer (NCT00002981); and comparison of PET/CT and whole body MRI for detecting skeletal and soft tissue metastases (NCT00375830). ${ }^{109}$

\section{Osteoporosis and Chemotherapy- Induced Bone Loss}

Osteoporosis remains a major, though preventable and treatable, public health threat for approximately 44 million Americans (55\% of persons aged $\geq 50$ years). ${ }^{168-170}$ In the United States, 10 million persons are currently estimated to have osteoporosis and nearly 34 million more are believed to have low bone mass, putting them at risk for this disease. ${ }^{168}$ Despite the availability of multiple therapies, the incidence of osteoporosis and its associated costs continue to increase worldwide. ${ }^{169}$ In particular, patients with cancer are at greater risk for developing osteoporosis and fractures, not only as a result of age-related bone loss but also because of their disease and treatment with hormone therapy, chemotherapy, or radiotherapy. ${ }^{171}$

\section{Defining and Quantifying Osteoporosis}

According to the National Institutes of Health Consensus Development Panel on Osteoporosis Prevention, Diagnosis, and Therapy, osteoporosis is defined as a "skeletal disorder characterized by compromised bone strength predisposing a person to increased risk of fracture." Bone strength represents both bone density and quality. Bone density is measured as grams of mineral per area or volume; it is quantified by peak bone mass and amount of bone loss. The quality of bone is represented by its architecture, turnover, mineralization, and damage. Fractures occur when a force (e.g., trauma) is exerted on osteoporotic bone. Therefore, the presence of osteoporosis represents a significant risk factor for future fracture. ${ }^{172}$

BMD testing is considered highly effective for establishing a diagnosis of osteoporosis and monitoring the disease. An inverse relationship exists between BMD and risk of fracture; that is, fracture risk increases as BMD decreases. The WHO defines osteoporosis as a BMD 2.5 or more standard deviations below the mean peak value of a "young normal" adult (T-score $\leq-2.5) .{ }^{173}$

Another way to measure BMD is to compare it with the mean value of normal subjects of the same age and sex (Z-score). In this manner, a $Z$-score less 
Lipton et al.

than -1 at the lumbar spine or proximal femur indicates a value in the lowest $25 \%$ of the reference range. At this value, fracture risk is almost doubled. A Z-score less than -2 indicates a value in the lowest $2.5 \%$ of the reference range, which translates to a substantially greater risk for fracture. ${ }^{170}$

\section{Risk Factors for Osteoporosis}

Several clinical risk factors have been associated with the development of osteoporosis, including low body mass index, previous clinical facture (excluding prior hip fracture), current cigarette smoking, alcohol use, and inflammatory diseases, such as rheumatoid arthritis or Crohn's disease. ${ }^{170,174}$ A study by Kanis et al. ${ }^{174}$ evaluated fracture risk using an assessment tool and showed that fracture probability typically increased with age and decreasing T-score. Furthermore, each clinical risk factor contributed to fracture risk and the differences in risk between women and men were similar at any given age and T-score, except in older persons. In this subgroup, risk for fracture was higher in women and attributed to their longer life expectancy. ${ }^{174}$ Other risk factors include cancer itself and the use of certain cancer therapies (e.g., chemotherapy, glucocorticoids, gonadotropin-releasing hormone [GnRH] antagonists, and AIs; Table 6). ${ }^{7,171,173}$

Osteoporosis affects both women and men. In men, risk factors for osteoporosis include prolonged exposure to certain medications (e.g., chronic glucocorticoid therapy, anticancer therapies), smoking, excessive alcohol use, and hypogonadism driven by increased use of ADT. ${ }^{173,176}$

\section{Implications of Cancer as a Chronic Disease}

Since the early 1990s, death rates from breast cancer have steadily decreased in women, with greater decreases seen in younger women $(<50$ years). During this time, death rates from prostate cancer have also decreased. ${ }^{177}$ As a result of improved detection and treatment, these cancers have evolved into chronic diseases with longer life expectancies. However, the quality of life for the years gained with better cancer therapies can be negatively impacted by treatmentrelated complications. Thus, long-term side effects associated with cancer therapies, including osteoporosis, may become increasingly problematic, and their management should be included in the comprehensive care of patients with cancer. ${ }^{178}$

\section{Pathways Leading to Gonadal Steroid Deficiency} and Osteoporosis

Various hormonal and nonhormonal therapies have the potential to cause bone loss by inducing hypogonadism, which increases bone resorption and turnover (Table 4). For men with prostate cancer, ADT through either bilateral orchiectomy or treatment with GnRH agonist or antagonist is associated with increased bone turnover, accelerated bone loss, and greater risk for fractures. Women with breast cancer are at increased risk for estrogen deficiency because of menopause, ovarian failure from systemic chemotherapy, or the use of drugs such as AIs and GnRH analogs. ${ }^{179}$ Surgical interventions, such as bilateral orchiectomy in prostate cancer and oophorectomy in breast cancer, can also lead to hypogonadism and bone loss and ultimately to osteoporosis in patients with hormone-sensitive tumors. ${ }^{171}$

\section{Clinical Trial Evidence of Osteoporosis in Women With Cancer}

Several clinical trials involving AIs in breast cancer have established their efficacy, as well as their potential to increase risk for fracture. ${ }^{180-184}$ Although data from the Arimidex, Tamoxifen, Alone or in Combination (ATAC) trial showed that the AI anastrozole was superior to tamoxifen in treating women with hormone receptor-positive disease, this trial also showed increased risk for anastrozole-associated fracture. ATAC researchers compared 5 years of adjuvant therapy with anastrozole, tamoxifen, or the combination in postmenopausal women with earlystage breast cancer $(\mathrm{N}=9366)$. Treatment with anastrozole resulted in a $17 \%$ reduction in relative risk of shortened disease-free survival and a 19\% improvement when compared with the combination group. However, fractures were significantly more common with anastrozole than with tamoxifen treatment. Fracture rates per 1000 woman-years were 22.6 for anastrozole and 15.6 for tamoxifen $(P<.001){ }^{180,181}$

Combined results from the Austrian Breast and Colorectal Cancer Study Group (ABCSG)-8 and the Arimidex-Nolvadex (ARNO) 95 trials $(\mathrm{N}=3224)$ showed statistically significantly more fractures with anastrozole therapy compared with tamoxifen in postmenopausal women with early-stage breast cancer ( $2 \%$ vs. $1 \%$, respectively; $P=.015) .{ }^{185}$ The Breast International Group (BIG) 1-98 Collaborative Group study was designed to compare letrozole with tamoxifen as adjuvant treatment for steroid 
hormone receptor-positive breast cancer in postmenopausal women $(\mathrm{N}=8010)$. Results from BIG 1-98 showed a significantly higher risk for fracture in postmenopausal women treated with letrozole for 5 years than in those treated with tamoxifen $(5.7 \%$ vs. $4.0 \% ; P<.001) .{ }^{184}$

Finally, the MA.17 trial also compared the effects of an AI with tamoxifen in patients with breast cancer $(\mathrm{N}=7757)$. Data from this trial showed that more fractures occurred with tamoxifen followed by letrozole versus placebo, though the difference was not significant $(5.3 \%$ vs. $4.6 \%$, respectively; $P=$ $.25)$. However, patients treated with letrozole were statistically significantly more likely to be diagnosed with new-onset osteoporosis $(8.1 \%$ vs. $6.0 \%$, respectively; $P=.003) .{ }^{182}$ A subsequent bone substudy of MA.17 showed a statistically significant decrease of 5.4\% $(P=.008)$ in lumbar spine BMD and a decrease of $3.6 \%(P=.044)$ in total hip BMD after 2 years of letrozole therapy. ${ }^{183}$

\section{Strategies to Prevent Bone Loss in Women Treated With Als}

Bisphosphonate therapy (alendronate, ibandronate, risedronate, or zoledronic acid) is recommended for women with osteoporosis. Bisphosphonates can be used alongside chemotherapy and endocrine therapy, ${ }^{173}$ and have been shown to prevent, reduce, and delay cancer-related skeletal complications. ${ }^{186}$ In the Zometa-Femara Adjuvant Synergy Trial (Z-FAST), Brufsky et al. ${ }^{187}$ evaluated the effects of zoledronic acid plus adjuvant letrozole in postmenopausal women with early-stage breast cancer $(\mathrm{N}=602)$. Patients were randomized to upfront zoledronic acid, $4 \mathrm{mg}$, intravenously every 6 months or delayed treatment with zoledronic acid (with post-baseline T-score decreased to $\leq-2$ or clinical fracture). At 24 months, the upfront treatment group showed a mean increase in lumbar spine BMD of 3.06\%, whereas the delayed treatment group had a mean decrease of $2.89 \%$ (5.9\% difference; $P<.001)$. Low- or non-trauma fractures occurred in $1.3 \%$ of patients in the upfront group and $1 \%$ in the delayed group. Overall, data showed that zoledronic acid could be combined with letrozole, was well tolerated, and prevented bone loss. ${ }^{187,188}$

In the ABCSG-12 trial, zoledronic acid, $4 \mathrm{mg}$, every 6 months effectively inhibited bone loss associated with adjuvant endocrine therapy in premenopausal patients with hormone-responsive breast cancer $(\mathrm{N}=400)$. Researchers compared combination

\begin{tabular}{|c|c|}
\hline Tumor Type & Therapy \\
\hline \multirow[t]{3}{*}{ Prostate cancer } & - Bilateral orchiectomies \\
\hline & $\begin{array}{l}\text { - Gonadotropin-releasing hormone } \\
\text { agonists }\end{array}$ \\
\hline & $\begin{array}{l}\text { - Gonadotropin-releasing hormone } \\
\text { antagonists }\end{array}$ \\
\hline \multirow[t]{3}{*}{ Breast cancer } & - Oophorectomy \\
\hline & $\begin{array}{l}\text { - Chemotherapy (cyclophosphamide, } \\
\text { selective estrogen-receptor } \\
\text { modulators) }\end{array}$ \\
\hline & - Aromatase inhibitors \\
\hline Osteosarcoma & - Methotrexate/ifosfamide \\
\hline $\begin{array}{l}\text { Hodgkin's/ } \\
\text { non-Hodgkin's } \\
\text { lymphoma }\end{array}$ & - Alkylating agents \\
\hline $\begin{array}{l}\text { Stem cell } \\
\text { transplantation } \\
\text { for various } \\
\text { malignancies }\end{array}$ & - Glucocorticoids/cyclosporine \\
\hline
\end{tabular}

Data from references 171 and 175 .

tamoxifen and goserelin with or without zoledronic acid, $4 \mathrm{mg}$, intravenously every 6 months with combination anastrozole and goserelin with or without zoledronic acid for 3 years in premenopausal women with hormone-responsive breast cancer. Endocrine treatment without zoledronic acid resulted in a statistically significant overall bone loss after 3 years of treatment $(P<.001$; BMD,$-14.4 \%$ after 36 months; mean T-score reduction, -1.4$)$. However, BMD remained stable in patients treated with zoledronic acid $(P<.001)$ versus endocrine therapy alone. ${ }^{189}$

Data from the Study of Anastrozole with the Bisphosphonate Risedronate (SABRE) trial showed increased BMD in postmenopausal women with hormone receptor-positive invasive breast cancer receiving adjuvant anastrozole plus risedronate $(\mathrm{N}=234)$. Patients were given anastrozole with or without risedronate based on their risk for fragility fracture. As shown in Figure 4, BMD was statistically significantly increased from baseline in the higher-risk stratum (anastrozole and risedronate; $P<.001$ ). In the moderate-risk group, anastrozole plus risedronate led to a statistically significant increase in lumbar spine BMD versus anastrozole plus placebo $(P<.001)$. The lower-risk group (anastrozole monotherapy) was associated with a nonsignificant increase in lumbar spine BMD at 12 months. ${ }^{190}$ 
Lipton et al.

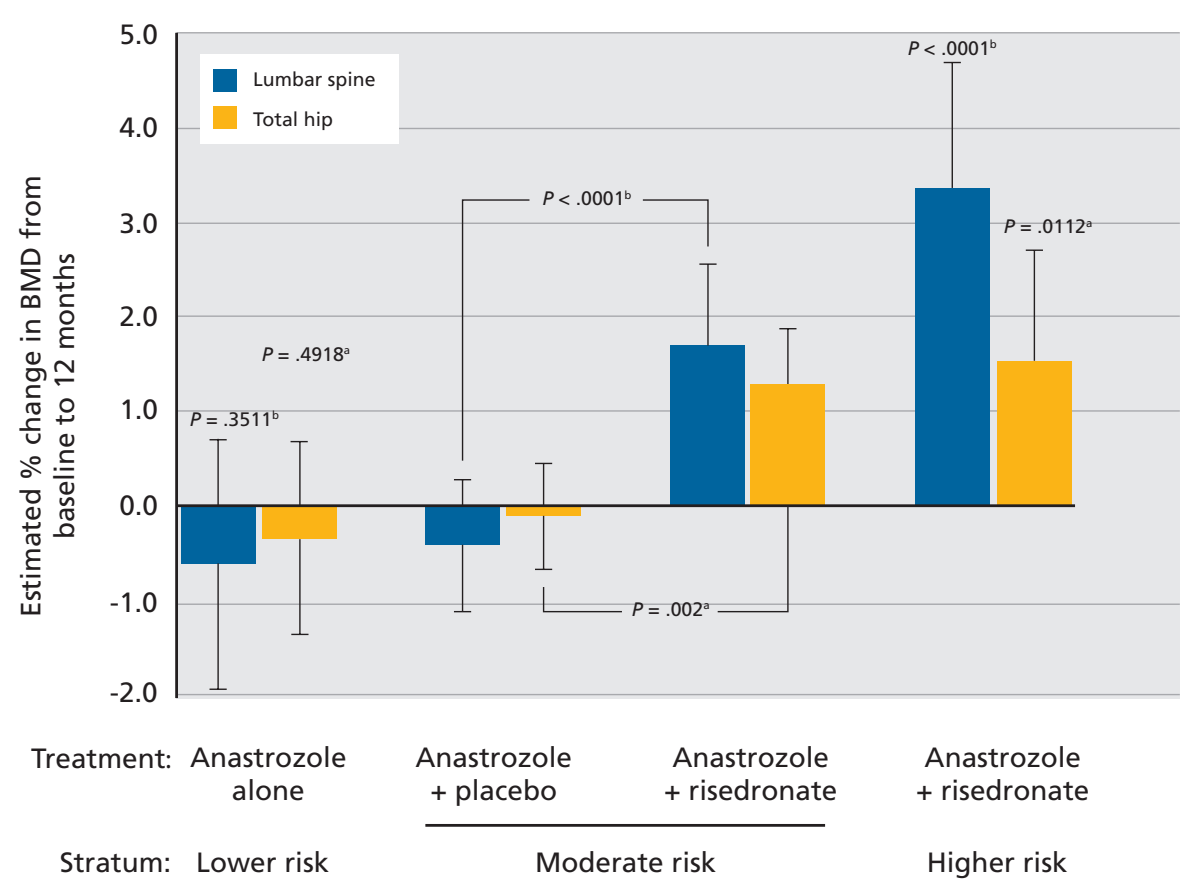

Figure 4 Estimated percent change and 95\% confidence intervals from baseline to 12 months in lumbar spine and total hip bone mineral density (BMD).

aP-values from paired t-rest for open-label, non-comparative groups.

${ }^{\mathrm{b}} \mathrm{P}$-values from ANCOVA in favor of anastrozole plus risedronate.

Reproduced with permission from Van Poznak C, Hannon RA, Clack G, et al. The SABRE (Study of Anastrozole with the Bisphosphonate RisedronatE) study: 12-month analysis [abstract]. Presented at 30th Annual San Antonio Breast Cancer Symposium; December 13-16, 2007; San Antonio, Texas. Abstract 502.

More recently, Ellis et al. ${ }^{191}$ evaluated the use of denosumab to protect against AI-induced bone loss. In this trial, women with hormone receptor-positive nonmetastatic breast cancer treated with adjuvant AI therapy were randomized to receive subcutaneous denosumab, $60 \mathrm{mg}$, or placebo every 6 months. Data showed that at 12 and 24 months, lumbar spine BMD increased by $5.5 \%$ and $7.6 \%$, respectively, in the denosumab group versus the placebo group $(P<.001$ for both time points). In addition, increases were observed as early as 1 month and were not affected by duration of AI therapy. The overall incidence of treatment-emergent adverse events was similar between groups. ${ }^{191}$

\section{Clinical Trial Evidence of Osteoporosis in Men With Cancer}

GnRH agonists are the mainstay therapy for prostate cancer, although osteoporosis has become an important and prevalent treatment-related adverse effect. A cohort study evaluating medical claims from Medicare beneficiaries showed that use of GnRH agonists significantly increased fracture risk in men with nonmetastatic prostate cancer $(\mathrm{N}=3887)$. The rate of any clinical fracture was 7.88 per 100 person-years in men treated with GnRH versus 6.51 per 100 personyears in matched controls $(P<.001)$. The rates of vertebral and hip/femur fractures were also significantly higher in men who received GnRH, and duration of therapy longer than 1 year was associated with a higher risk for fracture versus no GnRH therapy or GnRH therapy for less than 1 year. ${ }^{17}$

In another retrospective study, Shahinian et al. ${ }^{16}$ evaluated the medical records of men with prostate cancer $(\mathrm{N}=50,613)$ and showed that fracture-free survival decreased with cumulative exposure to ADT. In addition, after exposure to ADT, the rates of any fracture and fracture leading to hospitalization doubled. Of men surviving at least 5 years after diagnosis, $19.4 \%$ of those who underwent ADT experienced a fracture versus $12.6 \%$ of those who did not undergo ADT $(P<.001)$. A statistically significant 
relationship was seen between the number of doses of GnRH received during the 12 months after diagnosis and the subsequent risk of fracture $(P<.001) .{ }^{16}$

Mittan et al. ${ }^{192}$ examined the effects of $\mathrm{GnRH}$ analog treatment on bone loss and bone resorption in prostate cancer $(\mathrm{n}=15)$ and found that after 12 months of GnRH therapy, total hip and ultradistal radius BMD decreased significantly $(P<.001)$ compared with age-matched controls. The mean bone loss was $3.3 \%$ and $5.3 \%$, respectively. The observed reduction in BMD in the spine $(2.8 \%)$ and femoral neck $(2.3 \%)$ did not reach statistical significance and no significant bone loss was observed in control subjects. ${ }^{192}$

Recent data indicate that administering ADT treatment intermittently may attenuate spine and hip BMD decline after 3 years of treatment in men with prostate cancer. Spry et al. ${ }^{193}$ conducted a phase II individual cohort study of patients treated with flutamide and leuprolide ( $\mathrm{N}=72$ ) who had discontinued therapy once their PSA levels were less than $4 \mathrm{ng} / \mathrm{mL}$. At 3 years, osteoporosis increased from $7 \%$ at baseline to $10 \%$, and BMD of the hip and spine declined significantly after 9 months of treatment $(P<.001)$. However, further BMD decreases during the posttreatment period were attenuated at 1 year and 2 years later. Hip BMD decreased 0.6\% (nonsignificant $)$ and $0.8 \%(P<.014)$, respectively, and spine BMD increased $1.0 \%$ and $0.2 \%$, respectively (nonsignificant). Researchers concluded that intermittent ADT may reduce the risk of negative bone complications in men with prostate cancer. ${ }^{193}$

\section{Preventing Bone Loss in Men Treated With ADT}

Several small randomized controlled trials evaluated the effects of bisphosphonates on BMD in men receiving ADT for prostate cancer. In a 48-week, open-label study, Smith et al. ${ }^{194}$ compared the use of pamidronate, $60 \mathrm{mg}$, intravenously every 12 weeks in men with advanced or recurrent prostate cancer $(\mathrm{N}=47)$ without metastases treated with leuprolide. Men in this study also received supplemental calcium and vitamin D and were evaluated for secondary causes of osteoporosis. Results from this trial showed statistically significant increases in lumbar spine, total hip, and trochanter BMD at 12 months in those treated with pamidronate plus leuprolide versus leuprolide alone (Figure 5).

In another study, Smith et al. ${ }^{195}$ examined the effects of zoledronic acid on BMD in men with nonmetastatic prostate cancer $(\mathrm{N}=106)$ treated with
ADT. Treatment consisted of zoledronic acid, $4 \mathrm{mg}$, or placebo intravenously every 3 months for 1 year. Results from this study showed that mean BMD in the lumbar spine significantly increased by $5.6 \%$ in men treated with zoledronic acid and decreased by $2.2 \%$ in those given placebo $(P<.001)$. In addition, mean BMD of the femoral neck, trochanter, and total hip also increased in the zoledronic acid group and decreased in the placebo group. ${ }^{195}$

Less frequent therapy with an intravenous bisphosphonate may be sufficient to prevent bone loss in men receiving ADT. Michaelson et al. ${ }^{196} \mathrm{com}$ pared once-yearly administration of zoledronic acid, $4 \mathrm{mg}$, intravenously (on day 1 only) with placebo in men with prostate cancer receiving $\mathrm{GnRH}(\mathrm{N}=40)$. Data showed that a single treatment with zoledronic acid significantly increased lumbar spine and total hip BMD compared with placebo $(P<.001$ and $P$ $=.004$, respectively). Thus, once-yearly zoledronic acid may be an effective and more convenient strategy for preventing osteoporosis in men with prostate cancer treated with GnRH. ${ }^{196}$ A study by Greenspan et al. ${ }^{197}$ showed that weekly oral doses of alendronate, $70 \mathrm{mg}$, also provided BMD improvement versus placebo at the lumbar spine and total hip in men with nonmetastatic prostate cancer treated with ADT (N $=112$ ). After 1 year of alendronate, BMD increased by $3.7 \%(P<.001)$ at the spine, $0.7 \%(P=.031)$ at the total hip, and $1.6 \%(P=.008)$ at the femoral neck compared with placebo. ${ }^{197}$

Estrogens play a key role in the skeletons of men, as well as in women. ERs are expressed in osteoblasts and osteoclasts, and are involved in the regulation of bone formation and resorption. Data from Khosla et al. ${ }^{198}$ showed that estrogen was highly involved in the acquisition of bone mass in younger men and bone loss in older men. Men with inactivating mutations of ER- $\alpha$ and aromatase genes had very low bone mass. Furthermore, age-related decreases in bioavailable estradiol levels $(<50 \mathrm{pmol} / \mathrm{L})$ may be a major cause of bone loss in older men. ${ }^{198}$

Raloxifene is a SERM that mimics the effects of estrogens in bone without causing stimulatory effects in most other tissues. In a 12-month, open-label study, Smith et al. ${ }^{199}$ compared raloxifene plus GnRH with $\mathrm{GnRH}$ alone in nonmetastatic prostate cancer $(\mathrm{N}=$ 48). Their findings showed that raloxifene increased BMD at the lumbar spine $(1.0 \% \pm 0.9 \%)$ and total hip $(1.1 \% \pm 0.4 \%) .{ }^{199}$ More recently, Smith et al. ${ }^{200} \mathrm{ex}$ - 

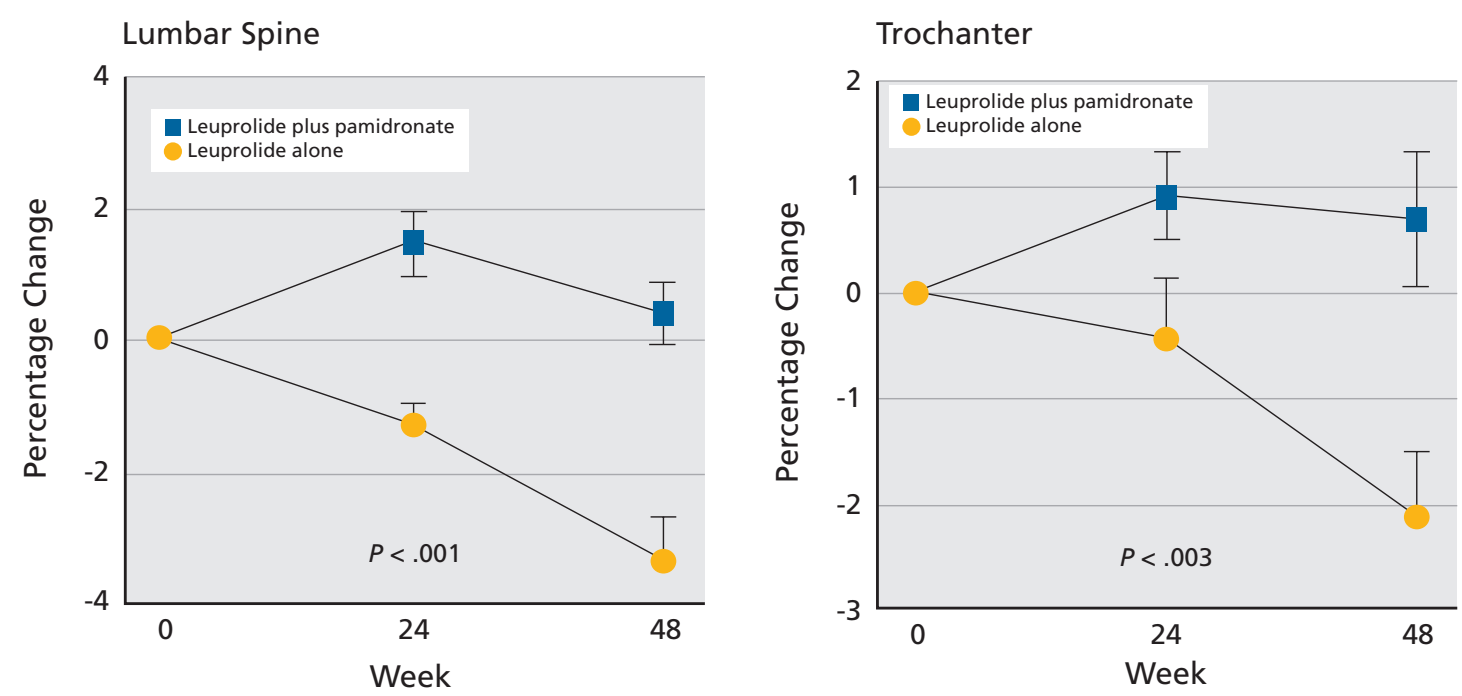

Femoral Neck
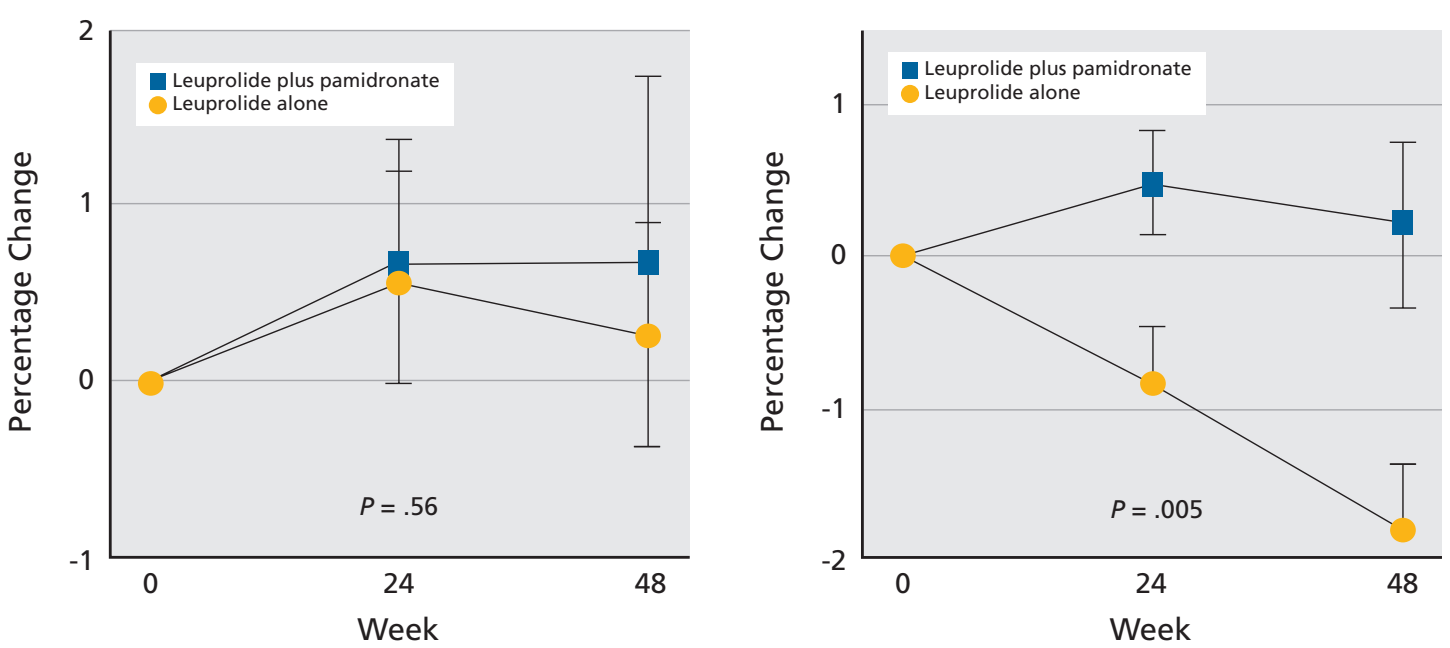

Figure 5 Mean ( \pm standard error) changed in baseline bone mineral density in men with prostate cancer treated with leuprolide or leuprolide plus pamidronate. $P$ value is between-group comparison of the percentage change from baseline to 48 weeks.

Reprinted with permission from Smith MR, McGovern FJ, Zietman AL, et al. Pamidronate to prevent bone loss during androgendeprivation therapy for prostate cancer. N Engl J Med 2001;345:948-955.

amined the effects of toremifene, another SERM, on $\mathrm{BMD}$ in men receiving ADT for prostate cancer $(\mathrm{N}$ = 1392). In this phase III multicenter, placebo-controlled, randomized trial, men received either $80 \mathrm{mg}$ of toremifene per day or placebo. Vertebral fracture, the primary end point, was used over other types of fracture because it can be reliably identified with serial radiographic imaging and is more common than other types of clinical fractures. Researchers also chose this end point because it is associated with other clinical fractures, as well as morbidity (kyphosis, loss of height, pain, impaired respiratory mechanics) and mortality. Secondary end points included BMD, lipids, breast symptoms, and hot flashes. ${ }^{200,201}$

In the planned interim analysis, researchers compared BMD changes from baseline to month 12 between the placebo and toremifene groups $(\mathrm{N}=$ 197). Compared with the placebo group, men in the toremifene group had significant increases in BMD at each evaluated skeletal site. Lumbar spine BMD decreased $0.7 \%$ in the placebo group and increased $1.6 \%$ in the toremifene group $(P<.001)$. Total hip BMD decreased $1.3 \%$ in the placebo group and increased $0.7 \%$ in the toremifene group $(P=.001)$. Femoral neck BMD decreased $1.3 \%$ in the placebo group and increased $0.2 \%$ in the toremifene group 
$(P=.009)$. Toremifene significantly decreased the incidence of new vertebral fractures by slightly more than $50 \%$, significantly increased lumbar spine and hip BMD, and also improved lipid parameters (total cholesterol, low-density lipoprotein, triglycerides, and high-density lipoprotein). ${ }^{200,201}$

In 2008, preliminary findings were released from a 3-year pivotal phase III placebo-controlled trial evaluating denosumab for the treatment of bone loss in men treated with ADT for nonmetastatic prostate cancer $(\mathrm{N}=1400)$. These data showed that denosum$\mathrm{ab}$ was associated with significantly greater increases in lumbar spine (primary end point) and nonvertebral BMD compared with placebo at multiple time points. During the 36-month evaluation period, denosumab reduced new vertebral fractures by $62 \%$. In addition, men treated with denosumab had fewer nonvertebral fractures over 3 years. The incidence and types of adverse events observed in this study were generally similar between the denosumab and placebo groups. ${ }^{202}$

\section{Managing Cancer-Related Bone Loss: Resources for Clinicians}

Several clinical practice guidelines, resources, and tools for the prevention, diagnosis, and management of bone loss in patients with different tumor types are available for clinicians, including:

- National Cancer Institute: PDQ Cancer Information Summaries (www.cancer.gov)

- National Osteoporosis Foundation: Clinician's Guide to Prevention and Treatment of Osteoporosis (www.nof.org)

- NCCN Clinical Practice Guidelines in Oncology: Guidelines for Treatment of Cancer by Site (www.nccn.org)

- FRAX: WHO Fracture Risk Assessment Tool (www.shef.ac.uk/FRAX)

- American Society of Clinical Oncology 2003 Update on the Role of Bisphosphonates and Bone Health Issues in Women With Breast Cancer (www.asco.org)

\section{References}

1. Theriault RL, Biermann JS, Brown E, et al. NCCN task force report: bone health and cancer care. J Natl Compr Canc Netw 2006;4(Suppl 2):S1-S22.

2. Roodman GD. Mechanisms of bone metastasis. N Engl J Med 2004;350:1655-1664
3. Coleman RE. Bisphosphonates: clinical experience. Oncologist 2004;9(Suppl 4):14-27.

4. Fidler IJ. Cancer metastasis. Br Med Bull 1991;47:157-177.

5. Mohler J, Amling CL, Bahnson RR, et al. NCCN clinical practice guidelines in oncology: prostate cancer, v.2.2009. Available at: http://www.nccn.org/professionals/physician_gls/PDF/prostate.pdf. Accessed May 21, 2009.

6. Carlson RW, Allred DC, Anderson BO, et al. NCCN clinical practice guidelines in oncology: breast cancer, v.1.2009. Available at: http://www.nccn.org/professionals/physician_gls/PDF/ breast.pdf. Accessed May 21, 2009.

7. Anderson KC, Alsina M, Bensinger $\mathrm{W}$, et al. NCCN clinical practice guidelines in oncology: multiple myeloma, v.2.2009. Available at: http://www.nccn.org/professionals/physician_gls/ PDF/myeloma.pdf. Accessed May 21, 2009.

8. Batson $\mathrm{O}$. The role of vertebral veins in metastatic processes. Ann Intern Med 1942;16:38-45.

9. Bundred N, Walker RA, Ratcliffe WA, et al. Parathyroid hormone related protein and skeletal morbidity in breast cancer. Eur J Cancer 1992;28:690-692.

10. Koenders PG, Beex LV, Langens R, et al. Steroid hormone receptor activity of primary human breast cancer and pattern of first metastasis. Breast Cancer Res Treat 1991;18:27-32.

11. Lipton A, Theriault RL, Hortobagyi GN, et al. Pamidronate prevents skeletal complications and is effective palliative treatment in women with breast carcinoma and osteolytic bone metastasis: long term follow-up of two randomized, placebo-controlled trials. Cancer 2000;88:1082-1090.

12. Joyce JA, Pollard JW. Microenvironmental regulation of metastasis. Nat Rev Cancer 2009;9:239-252.

13. Coleman RE. Skeletal complications of malignancy. Cancer 1997;80(8 Suppl):1588-1594.

14. Galasko C. The anatomy and pathways of skeletal metastases. In: Weiss L, Gilbert A, eds. Bone Metastases. Boston: G.K. Hall; 1981:49-63.

15. Krupski TL, Smith MR, Lee WC, et al. Natural history of bone complications in men with prostate carcinoma initiating androgen deprivation therapy. Cancer 2004;101:541-549.

16. Shahinian VB, Kuo YF, Freeman JL, Goodwin JS. Risk of fracture after androgen deprivation for prostate cancer. N Engl J Med 2005;352:154-164.

17. Smith MR, Lee WC, Brandman J, et al. Gonadotropin-releasing hormone agonists and fracture risk: a claims-based cohort study of men with nonmetastatic prostate cancer. J Clin Oncol 2005;23:7897-7903.

18. Malkowicz SB, Chu F, Forrest J, et al. Prevalence of osteoporosis and osteopenia during androgen deprivation (ADT) for prostate cancer: baseline data from a large randomized controlled trial [abstract]. J Clin Oncol 2007;25(18 Suppl):Abstract 5116.

19. American Cancer Society. Cancer Facts \& Figures 2008. Available at: http://www.cancer.org/downloads/ STT/2008CAFFfinalsecured.pdf. Accessed March 302009.

20. Ross FP. M-CSF, c-Fms, and signaling in osteoclasts and their precursors. Ann N Y Acad Sci 2006;1068:110-116.

21. Suda T, Takahashi N, Udagawa N, et al. Modulation of osteoclast differentiation and function by the new members of the tumor necrosis factor receptor and ligand families. Endocr Rev 1999;20:345-357.

22. Dai J, Hall CL, Escara-Wilke J, et al. Prostate cancer induces bone metastasis though Wnt-induced morphogenetic pro- 
Lipton et al.

tein-dependent and independent mechanisms. Cancer Res 2008;68:5785-5794.

23. Lessard L, Mes-Masson AM, Lamarre L, et al. NF-kappa B nuclear localization and its prognostic significance in prostate cancer. BJU Int 2003;91:417-420.

24. Fradet V, Lessard L, Bégin LR, et al. Nuclear factor kappa-B nuclear localization is predictive of biochemical recurrence in patients with positive margin prostate cancer. Clin Cancer Res 2004;10:8460-8464.

25. Cook RJ, Coleman R, Brown J, et al. Markers of bone metabolism and survival in men with hormone-refractory metastatic prostate cancer. Clin Cancer Res 2006;12:3361-3367.

26. Hofbauer LC, Schoppet M. Clinical implications of the osteoprotegerin/RANKL/RANK system for bone and vascular diseases. JAMA 2004;292:490-495.

27. Brufsky A. Management of cancer-treatment-induced bone loss in postmenopausal women undergoing adjuvant breast cancer therapy: A Z-FAST update. Semin Oncol 2006;33(Suppl 7):S13-17.

28. Huber DM, Bendixen AC, Pathrose P, et al. Androgens suppress osteoclast formation induced by RANKL and macrophagecolony stimulating factor. Endocrinology 2001;142:3800-3808.

29. Farhat GN, Taioli E, Cauley JA, et al. The association of bone mineral density with prostate cancer risk in the Osteoporotic Fractures in Men (MrOS) study. Cancer Epidemiol Biomarkers Prev 2009;18:148-154.

30. Hamaoka T, Madewell JE, Podoloff DA, et al. Bone imaging in metastatic breast cancer. J Clin Oncol 2004;22:2942-2953.

31. Langer CJ. Early detection, management, and evidence-based clinical guidelines for bone metastases: a 2006 update. Johns Hopkins Advanced Studies in Medicine 2006;6:S1057-1062.

32. Sadik M, Suurkula M, Höglund P, et al. Improved classifications of planar whole-body bone scans using a computer-assisted diagnosis system: a multicenter, multiple-reader, multiple-case study. J Nucl Med 2009;50:368-375.

33. Tian M, Zhang H, Endo K. Whole-body FDG-PET can provide more information than Tc-99m MDP bone scintigraphy for detection of bone metastases in patients with lung cancer [abstract]. J Clin Oncol 2005;23(18 Suppl):Abstract 2023.

34. Effert PJ, Bares R, Handt S, et al. Metabolic imaging of untreated prostate cancer by positron emission tomography with 18fluorine-labeled deoxyglucose. J Urol 1996;155:994-998.

35. Morris MJ, Scher HI. Clinical approaches to osseous metastases in prostate cancer. Oncologist 2003;8:161-173.

36. Even-Sapir E, Metser U, Mishani E, et al. The detection of bone metastases in patients with high-risk prostate cancer: $99 \mathrm{mTc}$ MDP Planar bone scintigraphy, single- and multi-field-of-view SPECT, 18F-fluoride PET, and 18F-fluoride PET/CT. J Nucl Med 2006;47:287-297.

37. Morrison MS, Ricketts S, Barnett J, et al. Monitoring tumor response to ZD4190 therapy with an 18F labeled angiogenesis imaging agent [abstract]. J Clin Oncol 2007;25(18 Suppl):Abstract 10507.

38. Watanabe H, Monzawa S, Adachi S, et al. Can PET/CT substitute for bone scintigraphy in assessment of bone metastases in lung cancer patients [abstract]? J Clin Oncol 2006;24(18 Suppl):Abstract 7203.

39. Beheshti M, Vali R, Waldenberger P, et al. The use of F-18 choline PET in the assessment of bone metastases in prostate cancer: correlation with morphological changes on CT. Mol Imaging Biol 2009; in press.

40. Venkitaraman R, Cook GJ, Dearnaley DP, et al. Does magnetic resonance imaging of the spine have a role in the staging of prostate cancer? Clin Oncol (R Coll Radiol) 2009;21:39-42.

41. Lecouvet FE, Geukens D, Stainier A, et al. Magnetic resonance imaging of the axial skeleton for detecting bone metastases in patients with high-risk prostate cancer: diagnostic and costeffectiveness and comparison with current detection strategies. J Clin Oncol 2007;25:3281-3287.

42. Frat $\mathrm{A}, \mathrm{Ag}$ ildere $\mathrm{M}, \mathrm{Gençog} \smile \mathrm{lu} \mathrm{A}$, et al. Value of whole-body turbo short tau inversion recovery magnetic resonance imaging with panoramic table for detecting bone metastases: comparison with 99MTc-methylene diphosphonate scintigraphy. J Comput Assist Tomogr 2006;30:151-156.

43. Engelhard K, Hollenbach HP, Wohlfart K, et al. Comparison of whole-body MRI with automatic moving table technique and bone scintigraphy for screening for bone metastases in patients with breast cancer. Eur Radiol 2004;14:99-105.

44. Schmidt GP, Schoenberg SO, Schmid R, et al. Screening for bone metastases: whole-body MRI using a 32-channel system versus dual-modality PET-CT. Eur Radiol 2007;17:939-949.

45. Skrinskas T, Clemons M, Freedman O, et al. Automated CTbased analysis to detect changes in the prevalence of lytic bone metastases from breast cancer. Clin Exp Metastasis 2009;26:97103.

46. Nackaerts K, Harper PG, Manegold C, et al. Management of bone metastases from lung cancer: consensus recommendations from an international panel [abstract]. J Clin Oncol 2008;26(18 Suppl):Abstract 19080 .

47. Coleman R, Smith P, Rubens R. Clinical course and prognostic factors following bone recurrence from breast cancer. Br J Cancer 1998; 77:336-340.

48. Wei B, Wang J, Bourne $\mathrm{P}$, et al. Bone metastasis is strongly associated with estrogen receptor-positive/progesterone receptornegative breast carcinomas. Hum Pathol 2008;39:1809-1815.

49. Conforti R, Xia W, Boulet T, et al. Cxcr4 expression and risk of bone metastasis in patients with early breast cancer [abstract]. J Clin Oncol 2007;25(18 Suppl):Abstract 10610.

50. Lipton A, Chapman JW, Demers L, et al. Use of elevated bone turnover to predict bone metastasis [abstract]. J Clin Oncol 2008;26(18 Suppl):Abstract 591.

51. Bentkover JD, Shaka EC, Thomas SK, et al. Diagnosis of bone metastases and utilization of bisphosphonates among advanced prostate cancer patients [abstract]. Presented at the 2006 ASCO Prostate Cancer Symposim; February 24-26, 2006; San Francisco, California. Abstract 165.

52. Pal RP, Thiruudaian T, Khan MA. When is a bone scan study appropriate in asymptomatic men diagnosed with prostate cancer? Asian J Androl 2008;10:890-895.

53. Chodak GW, Vogelzang NJ, Caplan RJ, et al. Independent prognostic factors in patients with metastatic (stage D2) prostate cancer. The Zoladex Study Group. JAMA 1991;265:618-621.

54. Ernst DS, Hanson J, Venner PM. Analysis of prognostic factors in men with metastatic prostate cancer. Uro-Oncology Group of Northern Alberta. J Urol 1991;146:372-376.

55. Akashi T, Furuya Y, Ohta S, Fuse H. Tissue factor expression and prognosis in patients with metastatic prostate cancer. Urology 2003;62:1078-1082. 
56. Smid M, Wang Y, Klijn JG, et al. Genes associated with breast cancer metastatic to bone. J Clin Oncol 2006;24:2261-2267.

57. Klein A, Olendrowitz C, Schmutzler R, et al. Identification of brain- and bone-specific breast cancer metastasis genes. Cancer Lett 2009;276:212-220.

58. Clar H, Langsenlehner U, Krippl P, et al. A polymorphism in the $G$ protein beta3-subunit gene is associated with bone metastasis risk in breast cancer patients. Breast Cancer Res Treat 2008;111:449-452.

59. Clar H, Renner W, Krippl P, et al. The LCT 13910 C/T polymorphism as a risk factor for osteoporosis, has no impact on metastatic bone disease in breast cancer. Breast Cancer Res Treat 2008;112:363-365.

60. Kominsky SL, Davidson NE. A "bone" fide predictor of metastasis? Predicting breast cancer metastasis to bone. J Clin Oncol 2006;24:2227-2229.

61. Kang Y, Siegel PM, Shu W, et al. A multigenic program mediating breast cancer metastasis to bone. Cancer Cell 2003;3:537549.

62. Kumazawa T, Tsuchiya N, Wang L, et al. Microsatellite polymorphism of steroid hormone synthesis gene CYP11A1 is associated with advanced prostate cancer. Int J Cancer 2004;110:140144.

63. Brown JE, Thomson CS, Ellis SP, et al. Bone resorption predicts for skeletal complications in metastatic bone disease. Br J Cancer 2003;89:2031-2037.

64. Brown JE, Cook RJ, Major P, et al. Bone turnover markers as predictors of skeletal complications in prostate cancer, lung cancer, and other solid tumors. J Natl Cancer Inst 2005;97:59-69.

65. Costa L, Demers LM, Gouveia-Oliveira A, et al. Prospective evaluation of the peptide-bound collagen type I cross-links Ntelopeptide and $\mathrm{C}$-telopeptide in predicting bone metastases status. J Clin Oncol 2002;20:850-856.

66. Coleman RE, Major P, Lipton A, et al. Predictive value of bone resorption and formation markers in cancer patients with bone metastases receiving the bisphosphonate zoledronic acid. J Clin Oncol 2005;23:4925-4935.

67. Morris MJ, Akhurst T, Osman I, et al. Fluorinated deoxyglucose positron emission tomography imaging in progressive metastatic prostate cancer. Urology 2002;59:913-918.

68. Chao TY, Lee SH, Chen MM, et al. Tartrate-resistant acid phosphatase 5b (TRAP 5b) as a serum marker of bone metastasis in breast cancer patients [abstract]. Proc Am Soc Clin Oncol 2002;21:Abstract 3013.

69. DiLiberto A, Schmidt W, Friedrich M. Prospective trial for clinical evaluation of TRACP $5 \mathrm{~b}$ as serum marker of bone resorption and for monitoring an oral clodronate - medication in osteolytic metastases of breast carcinoma [abstract]. J Clin Oncol 2004;22(18 Suppl):Abstract 862.

70. Ozu C, Nakashima J, Horiguchi Y, et al. Prediction of bone metastases by combination of tartrate-resistant acid phosphatase, alkaline phosphatase and prostate specific antigen in patients with prostate cancer. Int J Urol 2008;15:419-422.

71. de Jong IJ, Koopmans N, Breeuwsma AJ, et al. Bone turnover markers for the early detection of bone metastases in patients with prostate cancer [abstract]. Presented at the 2006 Presented at the 2006 ASCO Prostate Cancer Symposim; February 24-26, 2006; San Francisco, California. Abstract 145.

72. Kataoka A, Yuasa T, Kageyama S, et al. Diagnosis of bone metastasis in men with prostate cancer by measurement of serum
ICTP in combination with alkali phosphatase and prostatespecific antigen. Clin Oncol (R Coll Radiol) 2006;18:480-484.

73. Costa LA, Alho I, Casimiro S, et al. Markers of bone turnover (ICTP, NTX) and serum matrix metalloproteinase 1 (MMP1) as prognostic markers in breast cancer patients $(\mathrm{BC})$ with bone metastases (BM) treated with bisphosphonates (BP) [abstract]. J Clin Oncol 2008;26(18 Suppl):Abstract 1024.

74. Hall CL, Daignault SD, Shah RB, et al. Dickkopf-1 expression increases early in prostate cancer development and decreases during progression from primary tumor to metastasis. Prostate 2008;68:1396-1404.

75. Voorzanger-Rousselot N, Goehrig D, Journe F, et al. Increased Dickkopf-1 expression in breast cancer bone metastases. Br J Cancer 2007;97:964-970.

76. Zhang L, Hou X, Rao H, et al. Predictive significance of bone sialoprotein and osteopontin for bone metastases in resectable non-small cell lung cancer: a retrospective study [abstract]. J Clin Oncol 2007;25(18 Suppl):Abstract 7666.

77. Scagliotti G, Kalebic T, Volante M, et al. Bone sialoprotein is predictive of bone metastases in resectable non-small cell lung cancer: a retrospective case-control study. J Clin Oncol 2006;24:4818-4824.

78. Shoback D. Update in osteoporosis and metabolic bone disorder. J Clin Endocrinol Metab 2007;92:747-753.

79. van Beek ER, Cohen LH, Leroy IM, et al. Differentiating the mechanisms of antiresorptive action of nitrogen containing bisphosphonates. Bone 2003;33:805-811.

80. Alam AS, Bax CM, Shankar VS, et al. Further studies on the mode of action of calcitonin on isolated rat osteoclasts: pharmacological evidence for a second site mediating intracellular Ca2+ mobilization and cell retraction. J Endocrinol 1993;136:715.

81. McClung MR, Lewiecki EM, Cohen SB, et al. Denosumab in postmenopausal women with low bone mineral density. N Engl J Med 2006;354:821-831.

82. Reginster JY. Strontium ranelate in osteoporosis. Curr Pharm Des 2002;8:1907-1916.

83. Meunier PJ, Roux C, Seeman E, et al. The effects of strontium ranelate on the risk of vertebral fracture in women with postmenopausal osteoporosis. N Engl J Med 2004;350:459-468.

84. Reginster JY, Seeman E, De Vernejoul MC, et al. Strontium ranelate reduces the risk of nonvertebral fractures in postmenopausal women with osteoporosis: Treatment of Peripheral Osteoporosis (TROPOS) study. J Clin Endocrinol Metab 2005;90:2816-2822

85. Miller PD. Safety of parathyroid hormone for the treatment of osteoporosis. Curr Osteoporos Rep 2008;6:12-16.

86. U.S. Food and Drug Administration. Drugs@FDA: FDA Approved Drugs. Available at: http://www.accessdata.fda.gov/ Scripts/cder/DrugsatFDA/index.cfm. Accessed April 13, 2009.

87. Pavlakis N, Schmidt R, Stockler M. Bisphosphonates for breast cancer. Cochrane Database Syst Rev 2005;CD003474.

88. Powles T, Paterson A, McCloskey E, et al. Reduction in bone relapse and improved survival with oral clodronate for adjuvant treatment of operable breast cancer [ISRCTN83688026]. Breast Cancer Res 2006;8:R13.

89. Gnant M, Mlineritsch B, Schippinger W, et al. Endocrine therapy plus zoledronic acid in premenopausal breast cancer. $\mathrm{N}$ Engl J Med 2009;360:679-691. 
Lipton et al.

90. Winter MC, Thorpe HC, Burkinshaw R, et al. The addition of zoledronic acid to neoadjuvant chemotherapy may influence pathological response - exploratory evidence for direct anti-tumor activity in breast cancer [abstract]. Presented at the 2008 San Antonio Breast Cancer Symposium; December 10-14, 2008; San Antonio, Texas. Abstract 5101

91. Saarto T, Vehmanen L, Virkkunen P, Blomqvist C. Ten-year follow-up of a randomized controlled trial of adjuvant clodronate treatment in node-positive breast cancer patients. Acta Oncol 2004:43:650-656.

92. Hiraga T, Williams PJ, Ueda A, et al. Zoledronic acid inhibits visceral metastases in the 4T1/luc mouse breast cancer model. Clin Cancer Res 2004;10:4559-4567.

93. Giraudo E, Inoue M, Hanahan D. An amino-bisphosphonate targets MMP-9-expressing macrophages and angiogenesis to impair cervical carcinogenesis. J Clin Invest 2004;114:623-633.

94. Neville-Webbe HL, Rostami-Hodjegan A, Evans CA, et al. Sequence- and schedule-dependent enhancement of zoledronic acid induced apoptosis by doxorubicin in breast and prostate cancer cells. Int J Cancer 2005;113:364-371.

95. Lu S, Zhang J, Zhou Z, et al. Synergistic inhibitory activity of zoledronate and paclitaxel on bone metastasis in nude mice. Oncol Rep 2008;20:581-587.

96. Rack BK, Jueckstock J, Genss EM, et al. Effect of zoledronate on persisting isolated tumor cells in the bone marrow of patients without recurrence of early breast cancer [abstract]. Breast Cancer Res Treat 2007;106(Suppl 1):Abstract 511.

97. Reid IR. Osteonecrosis of the jaw: who gets it, and why? Bone 2009;44:4-10.

98. Cetiner S, Sucak GT, Kahraman SA, et al. Osteonecrosis of the jaw in patients with multiple myeloma treated with zoledronic acid. J Bone Miner Metab 2009;27:435-443.

99. Diel IJ, Weide R, Köppler H, et al. Risk of renal impairment after treatment with ibandronate versus zoledronic acid: a retrospective medical records review. Support Care Cancer 2009;17:719725.

100. Kintzel PE. Anticancer drug-induced kidney disorders. Drug Saf 2001;24:19-38.

101. Ibrahim A, Scher N, Williams G, et al. Approval summary for zoledronic acid for treatment of multiple myeloma and cancer bone metastases. Clin Cancer Res 2003;9:2394-2399.

102. Zometa [package insert]. East Hanover, NJ: Novartis Pharmaceuticals Corporation; 2008.

103. Aredia [package insert]. East Hanover, NJ: Novartis Pharmaceuticals Corporation; 2008.

104. Roodman GD. Biology of osteoclast activation in cancer. J Clin Oncol 2001;19:3562-3571.

105. Bekker PJ, Holloway DL, Rasmussen AS, et al. A single-dose placebo-controlled study of AMG 162, a fully human monoclonal antibody to RANKL, in postmenopausal women. J Bone Miner Res 2004;19:1059-1066.

106. Fizazi K, Lipton A, Mariette X, et al. Randomized phase II trial of denosumab in patients with bone metastases from prostate cancer, breast cancer, or other neoplasms after intravenous bisphosphonates. J Clin Oncol 2009;27:1564-1571.

107. Le Gall C, Bonnelye E, Clézardin P, et al. Cathepsin K inhibitors as treatment of bone metastasis. Curr Opin Support Palliat Care 2008;2:218-222.
108. Goblirsch M, Mathews W, Lynch C, et al. Radiation treatment decreases bone cancer pain, osteolysis and tumor size. Radiat Res 2004;161:228-234.

109. Bradley DA, Hussain M, Dipaola RS, Kantoff P. Bone directed therapies for prostate cancer. J Urol 2007;178;S42-48.

110. Tu SM, Kim J, Pagliaro LC, et al. Therapy tolerance in selected patients with androgen-independent prostate cancer following strontium-89 combined with chemotherapy. J Clin Oncol 2005;23:7904-7910.

111. Kyle RA, Gertz MA, Witzig TE, et al. Review of 1027 patients with newly diagnosed multiple myeloma. Mayo Clin Proc 2003;78:21-33.

112. Lipton A. Pathophysiology of bone metastases: how this knowledge may lead to therapeutic intervention. J Support Oncol 2004:2:205-220.

113. Roodman GD. Pathogenesis of myeloma bone disease. Leukemia 2009;23:435-441.

114. Roodman GD. Skeletal imaging and management of bone disease. Hematology Am Soc Hematol Educ Program 2008;2008:313-319.

115. Lipton A. Bisphosphonates and metastatic breast carcinoma. Cancer 2003;97(3 Suppl):848-853.

116. Yaneva MP, Goranova-Marinova V, Goranov S. Palliative radiotherapy in patients with multiple myeloma. J BUON 2006;11:43-48.

117. Basile A, Giuliano G, Scuderi V, et al. Cementoplasty in the management of painful extraspinal bone metastases: our experience. Radiol Med 2008;113:1018-1028.

118. Mont'alverne F, Vallée JN, Guillevin R, et al. Percutaneous vertebroplasty for multiple myeloma of the cervical spine. Neuroradiology 2009;51:237-242.

119. Hussein MA, Vrionis FD, Allison R, et al. The role of vertebral augmentation in multiple myeloma: International Myeloma Working Group Consensus Statement. Leukemia 2008;22:1479_ 1484.

120. Saliou G, Lehmann P, Vallée JN. Controlled segmental balloon kyphoplasty: a new technique for patients with heterogeneous vertebral bone density. Spine 2008;33:E216-220.

121. Ross JR, Saunders Y, Edmonds PM, et al. A systematic review of the role of bisphosphonates in metastatic disease. Health Technol Assess 2004;8:1-176.

122. Berenson JR, Lichtenstein A, Porter L, et al. Long-term pamidronate treatment of advanced multiple myeloma patients reduces skeletal events. Myeloma Aredia Study Group. J Clin Oncol 1998;16:593-602.

123. Rosen LS, Gordon D, Kaminski M, et al. Zoledronic acid versus pamidronate in the treatment of skeletal metastases in patients with breast cancer or osteolytic lesions of multiple myeloma: a phase III, double-blind, comparative trial. Cancer J 2001;7:377387.

124. Edwards BJ, Gounder M, McKoy JM, et al. Pharmacovigilance and reporting oversight in US FDA fast-track process: bisphosphonates and osteonecrosis of the jaw. Lancet Oncol 2008;9:1166-1172.

125. Fehm T, Beck V, Banys M, et al. Bisphosphonate-induced osteonecrosis of the jaw $(\mathrm{ONJ})$ : incidence and risk factors in patients with breast cancer and gynecological malignancies. Gynecol Oncol 2009;112:605-609. 
126. Gallego L, Junquera L. Consequence of therapy discontinuation in bisphosphonate-associated osteonecrosis of the jaws. Br J Oral Maxillofac Surg 2009;47:67-68.

127. Body JJ, Facon T, Coleman RE, et al. A study of the biological receptor activator of nuclear factor-kappa-B ligand inhibitor, denosumab, in patients with multiple myeloma or bone metastases from breast cancer. Clin Cancer Res 2006;12:1221-1228.

128. Vij R, Horvath N, Spencer A, et al. An open-label, phase 2 trial of denosumab in the treatment of relapsed $(R)$ or plateau-phase (PP) multiple myeloma (MM) [abstract]. Blood 2007;110:Abstract 1054.

129. Yaccoby S, Ling W, Zhan F, et al. Antibody-based inhibition of Dkk-1 suppresses tumor-induced bone resorption and multiple myeloma growth in vivo. Blood 2007;109:2106-2111.

130. Tian E, Zhan F, Walker R, et al. The role of the Wnt/b-catenin signaling antagonist Dkk-1 in the development of osteolytic lesions in multiple myeloma. N Engl J Med 2003;349:2483-2494.

131. Oyajobi BO, Garrett IR, Gupta A, et al. Stimulation of new bone formation by the proteasome inhibitor, bortezomib: implications for myeloma bone disease. Br J Haematol 2007;139:434-438.

132. Garrett IR, Chen D, Gutierrez G, et al. Selective inhibitors of the osteoblast proteasome stimulate bone formation in vivo and in vitro. J Clin Invest 2003;111:1771-1782.

133. Giuliani N, Morandi F, Tagliaferri S, et al. The proteasome inhibitor bortezomib affects osteoblast differentiation in vitro and in vivo in multiple myeloma patients. Blood 2007;110:334-338.

134. von Metzler I, Krebbel H, Hecht M, et al. Bortezomib inhibits human osteoclastogenesis. Leukemia 2007;21:2025-2034.

135. Roodman GD. Bone building with bortezomib. J Clin Invest 2008;118:462-464.

136. Breitkreutz I, Raab MS, Vallet S, et al. Lenalidomide inhibits osteoclastogenesis, survival factors and bone-remodeling markers in multiple myeloma. Leukemia 2008;22:1925-1932.

137. Martin TJ, Moseley JM. Mechanisms in the skeletal complications of breast cancer. Endocr Relat Cancer 2000;7:271-284.

138. Hortobagyi GN. Moving into the future: treatment of bone metastases and beyond. Cancer Treat Rev 2005;31(Suppl 3):9-18.

139. Ali SM, Leitzel K, Chinchilli VM, et al. Relationship of serum HER-2/neu and serum CA 15-3 in patients with metastatic breast cancer. Clin Chem 2002;48:1314-1320.

140. Alexandre J, Bleuzen P, Bonneterre J, et al. Factors predicting for efficacy and safety of docetaxel in a compassionate-use cohort of 825 heavily pretreated advanced breast cancer patients. J Clin Oncol 2000;18:562-573.

141. Sledge GW, Neuberg D, Bernardo P, et al. Phase III trial of doxorubicin, paclitaxel, and the combination of doxorubicin and paclitaxel as front-line chemotherapy for metastatic breast cancer: an intergroup trial (E1193). J Clin Oncol 2003;21:588592.

142. Mouridsen H, Gershanovich M, Sun Y, et al. Superior efficacy of letrozole versus tamoxifen as first-line therapy for postmenopausal women with advanced breast cancer: results of a phase III study of the International Letrozole Breast Cancer Group. J Clin Oncol 2001;19:2596-2606.

143. Jacobson AF, Shapiro CL, Van den Abbeele AD, Kaplan WD. Prognostic significance of the number of bone scan abnormalities at the time of initial bone metastatic recurrence in breast carcinoma. Cancer 2001;91:17-24.
144. Lipton A, Ali SM, Leitzel K, et al. Elevated serum Her-2/neu level predicts decreased response to hormone therapy in metastatic breast cancer. J Clin Oncol 2002;20:1467-1472.

145. Coleman RE, Rubens RD. The clinical course of bone metastases from breast cancer. Br J Cancer 1987;55:61-66.

146. Budd GT. Estrogen receptor profile of patients with breast cancer metastatic to bone marrow. J Surg Oncol 1983;249:167-169.

147. Hillner BE, Ingle JN, Chlebowski RT, et al. American Society of Clinical Oncology 2003 update on the role of bisphosphonates and bone health issues in women with breast cancer. J Clin Oncol 2003;21:4042-4057.

148. Tannock IF, de Wit R, Berry WR, et al. Docetaxel plus prednisone or mitoxantrone plus prednisone for advanced prostate cancer. N Engl J Med 2004;351:1502-1512.

149. Petrylak DP, Tangen CM, Hussain MH, et al. Docetaxel and estramustine compared with mitoxantrone and prednisone for advanced refractory prostate cancer. N Engl J Med 2004;351:1513_ 1520.

150. Kindrick AV, Grossfeld GD, Stier DM, et al. Use of imaging tests for staging newly diagnosed prostate cancer: trends from CaPSURE database. J Urol 1998;160:2102-2106.

151. Han M, Partin AW, Zahurak M, et al. Biochemical (prostate specific antigen) recurrence probability following radical prostatectomy for clinically localized prostate cancer. J Urol 2003;169:517-523.

152. Dall'era MA, Hosang N, Konety B, et al. Sociodemographic predictors of prostate cancer risk category at diagnosis: unique patterns of significant and insignificant disease. J Urol 2009;181:1622-1627.

153. Lee N, Fawaaz R, Olsson CA, et al. Which patients with newly diagnosed prostate cancer need a radionuclide bone scan? An analysis based on 631 patients. Int J Radiat Oncol Biol Phys 2000;48:1443-1446.

154. Abuzallouf S, Dayes I, Lukka H. Baseline staging of newly diagnosed prostate cancer: a summary of the literature. J Urol 2004;171:2122-2127.

155. Wymenga LF, Boomsma JH, Groenier K, et al. Routine bone scans in patients with prostate cancer related to serum prostatespecific antigen and alkaline phosphatase. BJU Int 2001;88:226230.

156. Yap BK, Choo R, Deboer G, et al. Are serial bone scans useful for the follow-up of clinically localized, low to intermediate grade prostate cancer managed with watchful observation alone? BJU Int 2003;91:613-617.

157. Gomez P, Manoharan M, Kim SS, Soloway MS. Radionuclide bone scintigraphy in patients with biochemical recurrence after radical prostatectomy: when is it indicated? BJU Int 2004;94:299-302.

158. Rigaud J, Tiguert R, Le Normand L, et al. Prognostic value of bone scan in patients with metastatic prostate cancer treated initially with androgen deprivation therapy. J Urol 2002;168:14231426.

159. Sabbatini P, Larson SM, Kremer A, et al. Prognostic significance of extent of disease in bone in patients with androgen-independent prostate cancer. J Clin Oncol 1999;17:948-957.

160. Keller ET, Brown J. Prostate cancer bone metastases promote both osteolytic and osteoblastic activity. J Cell Biol 2004;91:718-729. 
Lipton et al.

161. Carlin BI, Andriole GL. The natural history, skeletal complications, and management of bone metastases in patients with prostate carcinoma. Cancer 2000;88(12 Suppl):2989-2994.

162. Wada T, Nakashima T, Hiroshi N, Penninger JM. RANKLRANK signaling in osteoclastogenesis and bone disease. Trends Mol Med 2006;12:17-25.

163. Saad F, Gleason DM, Murray R, et al. Long-term efficacy of zoledronic acid for the prevention of skeletal complications in patients with metastatic hormone-refractory prostate cancer. J Natl Cancer Inst 2004;96:879-882.

164. Lynch CC, Hikosaka A, Acuff HB, et al. MMP-7 promotes prostate cancer-induced osteolysis via the solubilization of RANKL. Cancer Cell 2005;7:485-496.

165. Lara PN Jr, Stadler WM, Longmate J, et al. A randomized phase II trial of the matrix metalloproteinase inhibitor BMS-275291 in hormone-refractory prostate cancer patients with bone metastases. Clin Cancer Res 2006;12:1556-1563.

166. Carducci MA, Padley RJ, Breul J, et al. Effect of endothelin-A receptor blockade with atrasentan on tumor progression in men with hormone-refractory prostate cancer: a randomized, phase II, placebo-controlled trial. J Clin Oncol 2003;21:679-689.

167. Vogelzang NJ, Nelson JB, Schulman CC, et al. Meta-analysis of clinical trials of atrasentan $10 \mathrm{mg}$ in metastatic hormonerefractory prostate cancer [abstract]. J Clin Oncol 2005;23(18 Suppl):Abstract 4563

168. National Osteoporosis Foundation. Fast facts on osteoporosis, 2008. Available at: http://www.nof.org/professionals/Fast_ Facts_Osteoporosis.pdf. Accessed May 21, 2009.

169. Cole ZA, Dennison EM, Cooper C. Osteoporosis epidemiology update. Curr Rheumatol Rep 2008;10:92-96.

170. Eastell R. Treatment of postmenopausal osteoporosis. N Engl J Med 1998;338:736-746.

171. Guise TA. Bone loss and fracture risk associated with cancer therapy. Oncologist 2006;11:1121-1131.

172. NIH Consensus Development Panel on Osteoporosis Prevention, Diagnosis, and Therapy. Osteoporosis prevention, diagnosis, and therapy. JAMA 2001;285:785-795.

173. National Osteoporosis Foundation. Clinician's guide to prevention and treatment of osteoporosis. Available at: http://www. nof.org/professionals/NOF_Clinicians_Guide.pdf. Accessed May 21, 2009.

174. Kanis JA, Johnell O, Oden A, et al. FRAX and the assessment of fracture probability in men and women from the UK. Osteoporos Int 2008;19:385-397.

175. Pfeilschifter J, Diel IJ. Osteoporosis due to cancer treatment: pathogenesis and management. J Clin Oncol 2000;18:15701593.

176. National Osteoporosis Foundation. Osteoporosis: men. Available at: http://www.nof.org/men/index.htm. Accessed May 21, 2009.

177. American Cancer Society. Cancer Facts \& Figures 2008. Atlanta: American Cancer Society; 2008.

178. Hershman D, Narayanan R. Prevention and management of osteoporosis in women with breast cancer and men with prostate cancer. Curr Oncol Rep 2004;6:277-284.

179. Hoff AO, Gagel RF. Osteoporosis in breast and prostate cancer survivors. Oncology (Williston Park) 2005;19:651-658.

180. Howell A, Cuzick J, Baum M, et al. Results of the ATAC (Arimidex, Tamoxifen, Alone or in Combination) trial after comple- tion of 5 years' adjuvant treatment for breast cancer. Lancet 2005;365:60-62.

181. Baum M, Buzdar AU, Cuzick J, et al. Anastrozole alone or in combination with tamoxifen versus tamoxifen alone for adjuvant treatment of postmenopausal women with early breast cancer: first results of the ATAC randomised trial. Lancet 2002;359:2131-2139.

182. Goss PE, Ingle JN, Martino S, et al. Randomized trial of letrozole following tamoxifen as extended adjuvant therapy in receptor-positive breast cancer: updated findings from NCIC CTG MA.17. J Natl Cancer Inst 2005;97:1262-1271.

183. Perez EA, Josse RG, Pritchard KI, et al. Effect of letrozole versus placebo on bone mineral density in women with primary breast cancer completing 5 or more years of adjuvant tamoxifen: a companion study to NCIC CTG MA.17. J Clin Oncol 2006;24:3629-3635.

184. Thürlimann B, Keshaviah A, Coates AS, et al. A comparison of letrozole and tamoxifen in postmenopausal women with early breast cancer. N Engl J Med 2005;353:2747-2757.

185. Jakesz R, Jonat W, Gnant M, et al. Switching of postmenopausal women with endocrine-responsive early breast cancer to anastrozole after 2 years' adjuvant tamoxifen: combined results of ABCSG trial 8 and ARNO 95 trial. Lancet 2005;366:455-462.

186. Aapro M, Abrahamsson PA, Body JJ, et al. Guidance on the use of bisphosphonates in solid tumours: recommendations of an international expert panel. Ann Oncol 2008;19:420-432.

187. Brufsky A, Dong M, Lund K, et al. Twenty-four month follow-up of the effect of zoledronic acid on aromatase inhibitor associated bone loss in postmenopausal women with early breast cancer receiving adjuvant letrozole. Presented at the 2006 San Antonio Breast Cancer Symposium; December 14-17, 2006; San Antonio, Texas. Abstract 5060.

188. Brufsky A, Harker WG, Beck JT, et al. Zoledronic acid inhibits adjuvant letrozole-induced bone loss in postmenopausal women with early breast cancer. J Clin Oncol 2007;25:829-836.

189. Gnant MF, Mlineritsch B, Luschin-Ebengreuth G, et al. Zoledronic acid prevents cancer treatment-induced bone loss in premenopausal women receiving adjuvant endocrine therapy for hormone-responsive breast cancer: a report from the Austrian Breast and Colorectal Cancer Study Group. J Clin Oncol 2007;25:820-828.

190. Van Poznak C, Hannon RA, Clack G, et al. The SABRE (Study of Anastrozole with the Bisphosphonate Risedronate) study: 12-month analysis. Presented at the 2007 San Antonio Breast Cancer Symposium; December 13-16, 2007; San Antonio, Texas. Abstract 502.

191. Ellis GK, Bone HG, Chlebowski R, et al. Randomized trial of denosumab in patients receiving adjuvant aromatase inhibitors for nonmetastatic breast cancer. J Clin Oncol 2008;26:4875-4882.

192. Mittan D, Lee S, Miller E, et al. Bone loss following hypogonadism in men with prostate cancer treated with GnRH analogs. J Clin Endocrinol Metab 2002;87:3656-3661.

193. Spry NA, Galvão DA, Davies R, et al. Long-term effects of intermittent androgen suppression on testosterone recovery and bone mineral density: results of a 33-month observational study. BJU Int 2009;104:806-812.

194. Smith MR, McGovern FJ, Zietman AL, et al. Pamidronate to prevent bone loss during androgen-deprivation therapy for prostate cancer. N Engl J Med 2001;345:948-955.

195. Smith MR, Eastham J, Gleason DM, et al. Randomized controlled trial of zoledronic acid to prevent bone loss in men re- 
ceiving androgen deprivation therapy for nonmetastatic prostate cancer. J Urol 2003;169:2008-2012.

196. Michaelson MD, Kaufman DS, Kantoff P, et al. Randomized phase II study of atrasentan alone or in combination with zoledronic acid in men with metastatic prostate cancer. Cancer 2006;107:530-535.

197. Greenspan SL, Nelson JB, Trump DL, Resnick NM. Effect of once-weekly oral alendronate on bone loss in men receiving androgen deprivation therapy for prostate cancer: a randomized trial. Ann Intern Med 2007;146:416-424.

198. Khosla S, Melton LJ III, Atkinson EJ, O'Fallon WM. Relationship of serum sex steroid levels to longitudinal changes in bone density in young versus elderly men. J Clin Endocrinol Metab 2001;86:3555-3561.

199. Smith MR, Fallon MA, Lee H, Finkelstein JS. Raloxifene to prevent gonadotropin-releasing hormone agonist-induced bone loss in men with prostate cancer: a randomized controlled trial. J Clin Endocrinol Metab 2004;89:3841-3846.

200. Smith MR, Malkowicz SB, Chu F, et al. Toremifene increases bone mineral density in men receiving androgen deprivation therapy for prostate cancer: interim analysis of a multicenter phase 3 clinical study. J Urol 2008;179:152-155.

201. Smith $M$, Morton $R$, Wallace $H$, et al. A phase III randomized controlled trial of toremifene to prevent fractures and other adverse effects of androgen therapy in men with prostate cancer [abstract]. Presented at the 2008 American Association for Cancer Research Meeting; April 12-16, 2008; San Diego, California. Abstract LB-241.

202. Smith MR, Egerdie B, Hernández Toriz N, et al. A randomized, double-blind, placebo-controlled trial of denosumab in men receiving androgen deprivation therapy for non-metastatic prostate cancer. Presented at the 2009 European Association of Urology Meeting; March 17-21, 2009; Stockholm, Sweden. 